\title{
Sensitivity of Calanus spp. copepods to environmental changes in the North Sea using life-stage structured models
}

Maar, Marie; Møller, Eva Friis; Gürkan, Zeren; Jonasdottir, Sigrun; Nielsen, Torkel Gissel

Published in:

Progress in Oceanography

Link to article, DOI:

10.1016/j.pocean.2012.10.004

Publication date:

2013

Link back to DTU Orbit

Citation (APA):

Maar, M., Møller, E. F., Gürkan, Z., Jonasdottir, S., \& Nielsen, T. G. (2013). Sensitivity of Calanus spp. copepods to environmental changes in the North Sea using life-stage structured models. Progress in Oceanography, 111, 24-37. https://doi.org/10.1016/j.pocean.2012.10.004

\section{General rights}

Copyright and moral rights for the publications made accessible in the public portal are retained by the authors and/or other copyright owners and it is a condition of accessing publications that users recognise and abide by the legal requirements associated with these rights.

- Users may download and print one copy of any publication from the public portal for the purpose of private study or research.

- You may not further distribute the material or use it for any profit-making activity or commercial gain

- You may freely distribute the URL identifying the publication in the public portal 
Sensitivity of Calanus spp. copepods to environmental changes in the North Sea using life-stage structured models.

Marie Maar, ${ }^{*, 1}$ Eva Friis Møller, ${ }^{1}$ Zeren Gürkan, ${ }^{2}$ Sigrún H. Jónasdóttir, ${ }^{2}$ Torkel Gissel Nielsen ${ }^{2}$

1) Aarhus University, Department of Bioscience, Frederiksborgvej 399, P.O. Box 358, 4000 Roskilde, Denmark

2) The Technical University of Denmark, National Institute of Aquatic Resources, Charlottenlund Slot, 2920 Charlottenlund, Denmark.

*corresponding author: mam@dmu.dk, phone no: +45 87158572

1 
The copepods Calanus finmarchicus and C. helgolandicus co-exist in the North Sea,

4 but their spatial distribution and phenology are very different. Long-term changes in their

5 distributions seem to occur due to climate change resulting in a northward extension of $C$.

6 helgolandicus and a decline of $C$. finmarchicus in this region. The aim of this study is to use life-

7 stage structured models of the two Calanus species embedded in a 3D coupled hydrodynamic-

8 biogeochemical model to investigate how the biogeography of $C$. finmarchicus and $C$.

9 helgolandicus is modified by changes in $\pm 2^{\circ} \mathrm{C}$ sea water temperatures, overwintering and

10 oceanic inflow in the North Sea. Life-stage structured models are validated against CPR data

11 and vertical distributions north of the Dogger Bank in the North Sea for the reference year

12 2005. The model shows that 1$) \pm 2^{\circ} \mathrm{C}$ changes from the current level mainly influence the seasonal patterns and not the relative occurrence of the two species, 2) changes due to oceanic inflow mainly appeared in the northern and southern part of the North Sea connected to the NE Atlantic and not in the central part and 3) the abundance of Calanus species were very sensitive to the degree of overwintering within the North Sea because it allows them to utilize the spring bloom more efficiently and independently of the timing and amount of oceanic inflow. The combination of lower temperatures, higher overwintering and oceanic inflow simulating the situation in the 1960s largely favoured $C$. finmarchicus and their relative contribution to Calanus spp. increased from $40 \%$ in the reference year to $72 \%$. The $+2^{\circ} \mathrm{C}$ scenario suggest that in a warmer future, C. finmarchicus is likely to decline and C. helgolandicus abundance will probably continue to increase in some areas.

Keywords: 3D ecosystem model; life-stages; Calanus finmarchicus; Calanus helgolandicus; temperature; overwintering; oceanic inflow 


\section{INTRODUCTION}

The North Sea is a continental shelf system located in the North-East Atlantic Ocean and sustains a large fishery (Mackinson and Daskalov, 2007). The two copepods Calanus finmarchicus and $C$. helgolandicus are considered key species in the ecosystem because they serve as prey for commercially important fish species (Gaard and Reinert, 2002; Gislason and Astthorsson, 2002; Heath, 2007; Munk and Nielsen, 1994; Ringuette et al., 2002). However, long-term changes in the ecosystem have been linked to global warming resulting in a northward extension of $C$. helgolandicus and a decline of $C$. finmarchicus (Beaugrand et al., 2003; Beaugrand and Reid, 2003; Bonnet et al., 2005; Pitois and Fox, 2006; Planque and Fromentin, 1996). Since 1980, the spring phenology of temperature is advanced by 2.08 days per decade in the Northern Hemisphere (Burrows et al., 2011) and sea surface temperatures in the North Sea have been observed to increase about $1.5^{\circ} \mathrm{C}$ (Philippart et al., 2007). This is believed to have implications for the geographical distribution and seasonality of zooplankton (Mackas et al., 2012).

Morphologically, the two Calanus species are difficult to distinguish. Their life cycle includes eggs, six naupliar stages followed by five copepodite stages until maturation to the $6^{\text {th }}$ copepodite stage, the adult stage. Despite these similarities, the two species differ in the spatial distribution and phenology (Beaugrand et al., 2002; Bonnet et al., 2005). C. finmarchicus is a subarctic species occurring at latitudes 30 to $80^{\circ} \mathrm{N}$ with peak abundances at temperatures below $11^{\circ} \mathrm{C}$ (Bonnet et al., 2005; Helaouët and Beaugrand, 2007). Its lifecycle includes overwintering at 400 to 1400 m depth in the deep basins of the Norwegian Sea and the Norwegian Trench in the Skagerrak (Heath, 1999). Adults and the pre-adult copepodite stage 5 ascend in February-March and are advected into the North Sea until they start descending to diapause during summer and are practically absent from the surface waters in September (Heath et al., 1999; Jónasdóttir et al., 2005). In contrast, C. helgolandicus is a temperate species found at latitudes 15 to $65^{\circ} \mathrm{N}$ above the European shelf-edge with highest abundances at temperatures from 10 to $17^{\circ} \mathrm{C}$ (Bonnet et al., 2005; Helaouët and Beaugrand, 2007). C. helgolandicus diapause takes place at 400 to $800 \mathrm{~m}$ depth along the Atlantic margin or in deeper basins of the Mediterranean Sea (Bonnet et al., 2005; Williams and Conway, 1988). C. helgolandicus is observed from March to June in the southern part and from April to September in the central part of the North Sea (Bonnet et al., 2005; Jónasdóttir et al., 2005).

Because $C$. finmarchicus and $C$. helgolandicus have different phenology, changes in timing of life-stages and dominance from one to the other may cause changes in the size structure of available copepod prey for fish. Fish larvae have highly specific prey size 
preferences (Munk, 1992; Munk, 1997) and are sensitive to match-mismatch with suitable prey (Durant et al., 2005). Several studies have shown that the recruitment of sandeel, cod and herring were positively associated with Calanus abundance (Arnott and Ruxton, 2002; Beaugrand et al., 2003; Payne et al., 2009; van Deurs et al., 2009). Thus, bottom-up effects through prey abundance and size distribution seems important for the recruitment and development of fish. The shift from C. finmarchicus to $C$. helgolandicus in the North Sea has been documented as early as 1996 by Planque and Fromentin (1996). However, the understanding of the underlying mechanisms and their interactions is still limited (Beare et al., 2002; Beare and McKenzie, 1999; Reid et al., 2003).

To broaden this knowledge, the present study embeds stage-structured models of the two Calanus species in a 3D coupled hydrodynamic-biogeochemical model. The Calanus models are validated against CPR data as well as vertical distributions north of the Dogger Bank. The validated model is used to investigate the sensitivity of Calanus finmarchicus and $C$. helgolandicus distributions to changes in sea water temperatures, overwintering and oceanic inflow in the North Sea.

\section{DATA AND MODEL DESCRIPTION}

\subsection{The North Sea}

The North Sea (Figure 1) is a continental shelf sea with an average depth of $90 \mathrm{~m}$ and the deepest part ( $650 \mathrm{~m}$ ) is located in the Norwegian Trench in the Skagerrak. Water depth is generally higher in the northern part and gradually decreases towards the south. The northern part is characterized by seasonal stratification, whereas the southern part is subject to tidal mixing. The North Sea is influenced by North Atlantic Ocean inflow mainly from north along the edge of the continental shelf and to a lesser extent from the south through the English Channel. The inflow of $C$. finmarchicus are associated with the cold East Shetland Atlantic Inflow and Norwegian Coastal waters, whereas $C$. helgolandicus are associated with the warmer shelf-edge Atlantic water entering the North Sea via the Fair Isle Channel and the English Channel (Beare et al., 2002). Salinity ranges from 29 in the south-eastern German Bight to more than 35 in the northern part.

\subsection{CPR data}

Continuous Plankton Recorder (CPR) surveys are the best long-term data set of oceanic plankton in the North Sea and the North Atlantic Ocean and most of the plankton 
near-surface abundance data collected by the survey is available to the research community (Richardson et al., 2006). The CPR is deployed from ships of opportunity and towed along the routes at a depth of about 7 to $10 \mathrm{~m}$ (Pitois and Fox, 2006). We use CPR data from 2004 and 2005 (Johns, 2009) to generate model initial fields and boundary data of bulk zooplankton (biomass) and the two Calanus species (biomass and abundance), to calibrate mortality rates (2004) and to validate (2005) model results. The year 2005 is chosen because it is a typical year in terms of temperature anomalies for the period 1985 to 2007 (Hjøllo et al., 2009) and because the ratio of $C$. finmarchicus to Calanus spp. (34\%) is similar to the annual mean value for the period 2000 to 2008 ( $33 \% \pm 19 \%$ SE). Model abundances of the two Calanus species are compared with CPR data corrected for under-sampling (Pitois and Fox, 2006) for each of the CPR standard areas (B1, B2, C1, C2, D1, D2 and D3) in the North Sea (Figure 1). The size of areas $C 1$ and D3 are slightly reduced to eliminate subareas with no data coverage. Copepod biomasses (Calanus spp. and bulk) are estimated from CPR data (ind. $\mathrm{m}^{-3}$ ) using individual body dry weights (DW) of the most important copepod species in the area, i.e. Oithona spp., Corycaeus spp., Para-Pseudocalanus spp., Acartia spp., Pseudocalanus elongatus, Clausocalanus spp., Metridia spp., Temora longicornis, Isias clavipe, Centropages spp., Candacia spp., copepod nauplii and harpacticoids copepods. DW biomass is converted to mmol-N by a series of conversions using C/DW-ratio=0.45 (Brey, 2001), carbon weight of 12.0 $\mathrm{g} \mathrm{mol}^{-1}$, molar C:N-ratio of 5.0 for bulk zooplankton (Harris et al., 2000) and molar C:N-ratio of 5.7 for Calanus spp. (Møller et al., 2012).

\subsection{Other field data}

Data from the Arendal Station $\left(58^{\circ} 23 \mathrm{~N}, 8^{\circ} 49 \mathrm{E}\right.$, Figure 1 ) is used to force the seasonal vertical migration in the Skagerrak for 2004 and 2005. The data is based on depth-integrated samples from surface to $50 \mathrm{~m}$ with a WP2-net sampled in 2004 and 2005. Samples are collected 7 times from February to May and provided by Dr. Tone Falkenhaug, Institute of Marine Research in Norway (http://www.st.nmfs.noaa.gov/nauplius/media/timeseries/site northsea-arendal/). Furthermore, simulated vertical profiles of temperature, $\mathrm{Chl} a$ concentrations, and Calanus spp. are compared with field data from Station 1 (56 $\left.65 \mathrm{~N}, 3^{\circ} 45 \mathrm{E}\right)$, Station $3\left(56^{\circ} 35 \mathrm{~N}, 3^{\circ} 73 \mathrm{E}\right)$ and Station $5\left(56^{\circ} 05 \mathrm{~N}, 4^{\circ} 02 \mathrm{E}\right)$ from a field campaign north of the Dogger Bank (Figure 1) from 26 July to 2 August 2005 (Jónasdóttir and Koski, 2011). 
The integrated model system consists of a 3D circulation model coupled to a biogeochemical model and life stage-structured models of $C$. finmarchicus and $C$. helgolandicus. The model domain covers the North Sea and the Baltic Sea with a $6 \mathrm{~nm}$ horizontal resolution, but only the North Sea part is considered in the present study (Figure 1). The 3D circulation model is the Danish Meteorological Institute (DMI) operational ocean circulation model DMI-BSHcmod developed by BSH (Bundesamt fuer Seeschifffahrt und Hydrographie) and has been running operationally at DMI since 2001 (Larsen et al., 2007; She et al., 2007). The model has open lateral boundaries in the English Channel ( $4^{\circ} \mathrm{W}$ ) and the northern North Sea $\left(59.25^{\circ} \mathrm{N}\right.$ ) and is forced by hourly meteorological forcing (wind, air temperature, mean sea level pressure, surface humidity and cloud cover) based on DMI's operational version of the weather model HIRLAM (HIgh Resolution Limited Area Model) (Sass et al., 2002). Lateral temperature and salinity boundary conditions for the open North Sea boundaries are based on monthly climatologic fields. Sea level at the boundaries is prescribed as the sum of astronomic tides and surge predictions from a storm surge model covering the NE North Atlantic Ocean.

The Ecological ReGional Ocean Model (ERGOM) has previously been applied to the Baltic Sea (Neumann, 2000; Neumann and Schernewski, 2008) and later adapted to the North Sea by including sea water concentrations of silicate and microzooplankton as state variables and modifying light attenuation (Maar et al., 2011). ERGOM now contains 11 pelagic and 1 benthic state variables describing nitrogen cycling through 3 groups of phytoplankton (diatoms, flagellates and cyanobacteria), microzooplankton (protozoans and nauplii), mesozooplankton and detritus and changes in sea water concentrations of nutrients $\left(\mathrm{NO}_{3}\right.$, $\mathrm{NH}_{4}, \mathrm{PO}_{4}, \mathrm{SiO}_{2}$ ), dissolved $\mathrm{O}_{2}$ and organic matter in the sediment. The model is mass conserving for nitrogen $(\mathrm{N})$, whereas the dynamics of $\mathrm{PO}_{4}$ and $\mathrm{SiO}_{2}$ are coupled to that of nitrogen using a Redfield ratio and a variable $\mathrm{SiO}_{2}: \mathrm{N}$-ratio, respectively (Maar et al., 2011). ERGOM considers the processes of nutrient uptake, growth, grazing, mortality, pelagic- and benthic recycling, respiration, denitrification, nitrification, $\mathrm{N}_{2}$-fixation, and sedimentation. Further details of model configuration and validation can be found in Maar et al. (2011).

\subsection{Stage - structured models}

The applied stage-structured models of $C$. finmarchicus and $C$. helgolandicus were parameterized, validated and tested by Møller et al. (2012). These models were based on an original model for Pseudocalanus elongatus (Fennel, 2001) and later updated with new 
formulations of ingestion and stage transfer (Stegert et al., 2009). The model considers five life-stages, namely i) eggs-naupliar stage N2, ii) naupliar stages N3 - N6, iii) copepodite stages C1- C3, iv) copepodite stages C4-C5 and v) adults (Figure 2). The general scheme uses two sets of equations; one to describe the flux of biomass (nitrogen) through the group of stages, the other one to describe the flux of individuals. Nitrogen is chosen because it is more related to active biomass than carbon (Møller et al., 2012). Development is described by the change in mean individual weight (i.e. stage biomass divided by stage abundance) through gain (ingestion) and loss (egestion, respiration, excretion, mortality) of matter and moulting that depended on a critical moulting weight (Møller et al., 2012). The parameterizations of $C$. finmarchicus and C. helgolandicus models are based on literature values and grazing experiments (Møller et al., 2012). Both species have the same ingestion response (type III) to food concentration, whereas the dome-shaped ingestion response to temperature differ between the two species (Møller et al., 2012). The temperature optima for growth of adults are $12^{\circ} \mathrm{C}$ and $13.5^{\circ} \mathrm{C}$ for $\mathrm{C}$. finmarchicus and C. helgolandicus, respectively (Figure 3a). Growth rate of $C$. finmarchicus is higher than for $C$. helgolandicus at temperatures below $12^{\circ} \mathrm{C}$ and vice versa. When taking mortality into account, the temperature window for growth of the population is from 0 to $16^{\circ} \mathrm{C}$ for $\mathrm{C}$. finmarchicus and from 8 to $18^{\circ} \mathrm{C}$ for $\mathrm{C}$. helgolandicus (Figure 3b).

The stage-structured models are coupled to ERGOM through ingestion, egestion, respiration and mortality except for the first stage that is non-feeding (Figure 2). Both Calanus species are known to feed on both autotrophic and heterotrophic plankton prey (Maar et al., 2004). The size difference between the two Calanus species is not large compared to the size range of prey and they will approximately have the same prey size spectra (Hansen et al., 1997). We here choose the simplest assumption i.e. Calanus ingest autotrophic flagellates, diatoms and microzooplankton with the same prey preferences. There is no diel vertical migration of copepods in the model and this will be a topic for future model improvements.

Mortality rates of copepods control population abundance and biomass in the model, but only slightly development rates (Stegert et al., 2007). Daily mortality rates were based on an annual study of mortality of $C$. helgolandicus in the English Channel (Hirst et al., 2007) who supply general relationships between mortality and temperature and female $C$. helgolandicus abundance. They found that mortality is highest for eggs and early naupliar stages 1-2 and lower for the other naupliar stages and adults. There is no data on copepodite stages C1-C4, 
but we use the same mortality as for adults in the model. For eggs to N2 we used the mortality $\left(M_{e g g} \mathrm{~d}^{-1}\right)$ related to the abundance of females $\left(F_{a}\right.$, ind. $\left.\mathrm{m}^{-3}\right)$ due to cannibalisms on eggs:

where $\alpha=2.142 \mathrm{~d}^{-1}$ for both species and $\beta=0.32$ female $^{-1} \mathrm{~d}^{-1}$ and 0.16 female ${ }^{-1} \mathrm{~d}^{-1}$ for $C$. finmarchicus and $C$. helgolandicus, respectively. The $\beta$ of $C$. finmarchicus is corrected due to the half-size of their eggs compared with C. helgolandicus eggs (Møller et al., 2012). To reduce the mortality at very low numbers and thereby stabilise the model, a type II saturation function for adults is applied to the temperature $(T)$ dependent mortality $\left(M, \mathrm{~d}^{-1}\right)$ from Hirst et al. (2007) (Stegert et al., 2009):

$$
M_{e g g}=\alpha+\beta \times F_{a}
$$

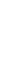


Model boundary data of bulk mesozooplankton and C4 to adults of Calanus spp. is based on monthly averaged CPR data (see above). Vertical distributions are assumed to be homogeneous at the boundary. Influx of $C$. finmarchicus adults from the North Atlantic Ocean covers the whole northern model boundary, while influx is set to zero at the boundary in the English Channel (Figure 4a). C. helgolandicus is assumed to enter the North Sea through the Fair Isle Current $<0^{\circ} \mathrm{E}$ at the northern model boundary and along the boundary in the English Channel. No species specific data are available for Calanus spp. eggs, nauplii and C1 to C3 abundances and we use zero-gradient at the boundaries i.e. the abundance in the incoming water is the same as inside the model domain. A small fraction of the adult population of both species seems to overwinter in surface waters in some areas of the North Sea according to CPR data from January (Figures 4c, d). Therefore, $C$. finmarchicus is initialised using a constant vertical abundance of 1.0 ind. $\mathrm{m}^{-3}$ in the deeper areas with a water column depth $>110 \mathrm{~m}$ (Figure 1). C. helgolandicus is initialised using a function of abundance versus latitude based on average January abundances from the CPR standard areas. The two Calanus species diapause in the bottom layer of the Norwegian trench (Fransz et al., 1991). We therefore use data from the Arendal Station in the Skagerrak to force the seasonal vertical migration of the two Calanus species. C. finmarchicus is set to ascend from diapause in the Norwegian Trench as adults in February and as C4 to C5 from February to April (Figure 5b). C. helgolandicus ascend as C4, C5 and adults in April (Figure 5c). C. finmarchicus has been reported to descend for diapause at stages $C 5$ to adults in late summer (Fransz et al., 1991). This was included in the model as a downward migration of $3 \mathrm{~m} \mathrm{~d}^{-1}$ from day 215 for stages C4 to adults based on CPR data. An improved model description of seasonal vertical migration will be tested in future model versions.

\subsection{Model validation using CPR data}

CPR data only distinguish between $C$. finmarchicus and $C$. helgolandicus at the two final stages ( $C 5$ to adults), whereas stages $\mathrm{C} 1$ to $\mathrm{C} 4$ are considered as Calanus spp. This stage separation is not consistent with our model structure. We therefore chose to compare the sum of the model stages 'C4 to adults' with CPR data of 'C5 to adults' for each of the two Calanus species. Model stages 'C1 to C3' of Calanus spp. showed similar patterns to that of 'C4 to adults' and is not shown. Bulk zooplankton is validated in another study (Maar et al., unpublished data).

We use correlation analysis $(p<0.05)$ of monthly means of abundances for all CPR standard areas to test the model capability to reproduce the seasonal distributions. The model 
bias $(M B)$ is used to evaluate if the model over- or underestimated abundances in the different CPR areas:

$$
M B=\sum_{i=1}^{N} \frac{\left(M_{i}-D_{i}\right)}{\bar{D}}
$$

where $M$ is monthly model abundances, $D$ is monthly CPR abundances, $N$ is the number of monthly means in each area and $\bar{D}$ is the average CPR abundance in the respective area. In addition, the MB was estimated for the seasonal distribution using monthly averages from all areas.

\subsection{Scenarios}

The validated model (2005) is referred to as the reference run (REF). Five different scenarios are carried out to test the sensitivity of the two Calanus species to changes in temperature and oceanic inflow (Table 2). The same initial conditions and forcing are used for the sensitivity scenarios and REF with the exception of the following specific changes. Sea surface water temperatures in the North Sea have been observed to increase about $1.5^{\circ} \mathrm{C}$ since 1980 (Philippart et al., 2007). Previous model simulations with NORWECOM for the period 1985 to 2007 additionally found that surface anomalies roughly varied within $\pm 2^{\circ} \mathrm{C}$ in the North Sea (Hjøllo et al., 2009). Projections of climate change suggest that the current warming is likely to continue with additional increases of $+2^{\circ} \mathrm{C}$ in the next 100 years (Philippart et al., 2007). Therefore, in the first two sensitivity scenarios, sea water temperatures are changed with either $-2^{\circ} \mathrm{C}$ (scenario $-2 \mathrm{~T}$ ) or $+2^{\circ} \mathrm{C}$ (scenario $+2 \mathrm{~T}$ ) over the whole model domain but only for temperature dependent rates in the biogeochemical and Calanus models. The timing of diapause is set to two weeks earlier (later) at $2^{\circ} \mathrm{C}$ higher( lower) temperatures to keep the time span of feeding in the surface layer constant (Hjøllo et al., 2012). Hydrodynamics are not altered by the sea water temperature changes. In scenario -INI, initial abundance of Calanus is changed to mimic overwintering in surface waters according to CPR abundances from the 1960s (Figures 4c, d). This means that the initial abundance of $C$. finmarchicus is increased by an average factor of 7.0 and C. helgolandicus is decreased by an average factor of 0.2 in comparison with the reference year 2005. In addition, we test the influence of oceanic inflow 
of Calanus in two scenarios by changing model boundary conditions. In these scenarios, the abundance of $C$. finmarchicus is increased by a factor of 2.0 (Figure $4 \mathrm{a}$ ) and $C$. helgolandicus is decreased by a factor of 0.2 (Figure $4 \mathrm{~b}$ ) at the northern boundary and in the Norwegian Trench (scenario BCAL) corresponding to the situation in 1960's. In addition, we use sea water levels from 1965 at the boundaries from a 2D surge model of the North Atlantic Ocean provided by DMI. The altered inflow is then combined with the settings in scenario -2T and INI (scenario 2 TIB) to correspond to the overall conditions in the 1960s. The effects of the scenarios are assessed as the mean difference in abundance from REF during the productive period March to October. We consider the model sensitivity studies as useful and simple tools that give an indication of the range of effects from the tested forcing factors and the resulting outcome of the distribution of the two dominant Calanus species in the North Sea. It is out of scope of the present study to consider other climatic changes (e.g. wind, short wave radiation, etc.) on the ecosystem or to provide long-term model data.

292

\section{RESULTS}

3.1. Overall model patterns in the reference run

Annual-averaged surface temperatures showed up to $5^{\circ} \mathrm{C}$ higher values in the southern English Channel in comparison to the NW North Sea in REF (Figure 6a). Chl a concentrations were patchily distributed but generally higher along the coast (Figure 6b). Microzooplankton and mesozooplankton biomass were highest in the southern part, on Dogger Bank and along the coast (Figures $6 c-d$ ). Annual-averaged $C$. finmarchicus abundance was highest at the northern boundary and along the Norwegian coast and declined drastically towards south (Figure 6e). Annual-averaged abundance of $C$. helgolandicus was highest at the southern and north-western boundaries and along the Norwegian coast and at intermediate levels in the Dogger Bank area (Figure 6f). They occurred in low numbers in the German Bight and north of Dogger Bank.

The simulated relative frequency of surface temperatures and of the two Calanus species (nauplii to adults) at temperature intervals of $1^{\circ} \mathrm{C}$ ranging from 0 to $22^{\circ} \mathrm{C}$ from March to October is shown in figure 7. Temperature showed a bimodal pattern with peaks at 6 to $7^{\circ} \mathrm{C}$ and 14 to $17^{\circ} \mathrm{C}$. Distributions of $C$. finmarchicus and $C$. helgolandicus were both dome-shaped within the temperature intervals from 3 to $17^{\circ} \mathrm{C}$ and 4 to $19^{\circ} \mathrm{C}$, respectively. Peak abundances 
For the validation year 2005 (REF), the model was able to reproduce the overall seasonal and spatial patterns according to CPR data within the North Sea (Figures 8 and 9). The correlations between monthly means of CPR data and model data were high with $R^{2}=0.89$ $(p<0.05, n=12)$ and $R^{2}=0.68(p<0.05, n=12)$ for $C$. finmarchicus and $C$. helgolandicus, respectively. Annual averages were underestimated by 11 and $22 \%$ for $C$. finmarchicus and $C$. helgolandicus, respectively, in the model. CPR abundances of $C$. finmarchicus were highest in areas B1, B2 and C2 and the model bias was -12 to $47 \%$ (Figure 8). In D1 and D2 areas, CPR abundances were very low except for one peak in May in area D2 that was not reproduced by the model. These high values were sampled on the border to area $\mathrm{C} 2$ and may not be representative for area D2. C. finmarchicus were totally absent in the southern area D3 according to CPR data and model. For $C$. helgolandicus, model abundances were underestimated with -51 and $-57 \%$ in areas B1 and D2 (Figure 9). The contribution of $C$. finmarchicus to Calanus spp. was $40 \%$ on average in the model and slightly higher than the ratio of $33 \%( \pm 19 \% \mathrm{SE})$ based on CPR data (Figure 10). thermocline and a deep Chl a maximum (DCM) located at 25 to $40 \mathrm{~m}$ depth (Figures 11a, b). Temperatures were $15^{\circ} \mathrm{C}$ at the surface and $6^{\circ} \mathrm{C}$ at the bottom. The model showed overall the same pattern with stratification and a DCM. It did, however, overestimate surface water temperatures by $1.5^{\circ} \mathrm{C}$ and $\mathrm{Chl} a$ concentrations by $0.5 \mathrm{mg} \mathrm{m}^{-3}$ and DCM was located approximately $5 \mathrm{~m}$ higher in the water column at St. 5 (Figure 11b) than observations showed. The vertical distribution profiles of $C$. finmarchicus females showed a peak coinciding with the DCM both in ground truth data and model (Figure 11c). The observed vertical distribution of females of $C$. helgolandicus in contrast to $C$. finmarchicus showed higher values in the surface mixed layer with a peak at $15 \mathrm{~m}$ depth (Figure 11d). The model however, gave higher abundances in the surface layer $<30 \mathrm{~m}$ depth but without a pronounced peak at $15 \mathrm{~m}$ depth. Correlation analysis for all three stations together $(n=15)$ gave $R^{2}=0.97,0.48,0.75$ and 0.55 for temperature, $\mathrm{Chl}$ a, C. finmarchicus and C. helgolandicus, respectively, at a confidence level of $5 \%$.

3.3. Forcing effects on seasonal distributions 
caused an earlier or later termination of the spring bloom, respectively. Area-averaged abundance of $C$. finmarchicus increased from the beginning of May with a seasonal peak in beginning of July in REF (Figure 12c). For C. helgolandicus, abundances increased from midMay with a small peak in mid-June and a larger one in mid-October in REF (Figure 12d). The first seasonal increase in abundances of $C$. finmarchicus and $C$. helgolandicus were accelerated with app. 2 weeks at higher temperatures $(+2 T)$ and similarly delayed at lower temperatures $(-2 T)$ in comparison with REF (Figures 12c, d). The peak-of-season estimated by an annual 'center-of-gravity' index (Mackas et al., 2012) was day 170 (18 June) and day 200 (29 July) in REF for C. finmarchicus and C. helgolandicus, respectively. Peak-of-season changed with +20 and -15 days in $-2 \mathrm{~T}$ and $+2 \mathrm{~T}$, respectively, of $C$. finmarchicus, +6 and -21 days in $-2 \mathrm{~T}$ and $+2 \mathrm{~T}$, respectively, of $C$. helgolandicus.

At $2^{\circ} \mathrm{C}$ lower temperatures (-2T), C. finmarchicus increased in the north-western part and decreased in the north-eastern part due to the dome-shaped temperature response

357 (Figure 13a). C. helgolandicus increased in abundance in the central North Sea (51 to $56^{\circ} \mathrm{N}$ ) and 358 in the Skagerrak, but decreased in the north-western part (Figure 13b). Higher temperatures $359(+2 T)$ caused lower abundances of $C$. finmarchicus except for north of Dogger Bank (Figures 360 13c). C. helgolandicus mainly decreased in abundance in the central part, but increased in the English Channel and Fair Isle Channel (Figure 13d). The change caused by temperature changes was generally \pm 10 ind. $\mathrm{m}^{-3}$ (Figures 13a-d). The scenario with altered initial conditions (INI) resulted in $<15$ ind. $\mathrm{m}^{-3}$ higher abundances of $C$. finmarchicus in the western part southwards to $52^{\circ} \mathrm{N}$ (Figure 13e) and in a reduction of $<5$ ind. $\mathrm{m}^{-3}$ of $C$. helgolandicus in the areas less influenced by the boundaries (Figures 13f). Changes in oceanic inflow (BCAL) caused higher (lower) abundances at the northern boundary from -2 to $3^{\circ} \mathrm{E}\left(<-2\right.$ and $\left.>3^{\circ} \mathrm{E}\right)$ for both Calanus species (Figures 13g-h). Furthermore, C. finmarchicus increased in the Skagerrak/NE part and in a patch towards the British coast with up to 15 ind. $\mathrm{m}^{-3}$. In contrast, $C$. helgolandicus decreased in numbers $\left(<15\right.$ ind $\left.\mathrm{m}^{-3}\right)$ in the English Channel, the Norwegian Trench and in some spots in the central North Sea. The combined effects of lower temperature, changes in initial abundances and oceanic inflow (-2TIB) reinforced the patterns in the previous scenarios $-2 T$,

$372 \mathrm{INI}$ and BCAL (Figures 13i-j). The relative abundance of $C$. finmarchicus to total Calanus spp. 373 abundance changed from $40 \%$ in REF to $41 \%, 38 \%, 66 \%, 50 \%$ and $72 \%$ in $-2 \mathrm{~T},+2 \mathrm{~T}$, INI, BCAL 374 and -2 TIB, respectively (Figure 10 ). The value of -2 TIB $(72 \%)$ was similar to the ratio of $81 \%$ $\pm 29 \%$ SE, respectively, based on CPR data from the 1960 s. 
The vertical distribution of both Calanus species north of Dogger Bank were moved 5 to $10 \mathrm{~m}$ up in the water column at $2^{\circ} \mathrm{C}$ lower temperatures in comparison with the reference run, i.e. more $C$. finmarchicus was found in DCM and the small subsurface peak of $C$. helgolandicus disappeared and the majority was found in the upper layers (Figure 14). At $2^{\circ} \mathrm{C}$ higher temperatures, the model suggested that $C$. finmarchicus kept primarily in bottom waters, whereas $C$. helgolandicus had its peak concentration at 30 to $40 \mathrm{~m}$ in the DCM rather than at the surface in comparison with the reference run.

\section{DISCUSSION}

4.1. Sensitivity of Calanus distributions

A regime shift has occurred in the North Sea during the period 1982 to 1988 which has resulted in marked changes in the food web (Beaugrand, 2004). Specifically in the mesozooplankton community, the ecologically important copepod $C$. finmarchicus has declined in abundance, whereas $C$. helgolandicus has propagated further north. The underlying mechanisms have been suggested to be increasing sea water temperatures and/or changes in oceanic inflows but their relative impact is unknown (Beare et al., 2002; Beare and Mckenzie, 1999; Reid et al., 2003). The present model study is the first to combine hydrodynamic biogeochemical modeling with stage-structured models of both Calanus species in the North Sea and to investigate the sensitivity of the populations to these specific environmental changes.

The inflow of $C$. finmarchicus has been associated with the cold East Shetland Atlantic Inflow (ESAI), whereas $C$. helgolandicus are associated with the warmer shelf-edge Atlantic water (SAW) entering the North Sea via the Fair Isle Channel and the English Channel (Beare et al., 2002). We found that changes in inflow patterns and higher boundary abundances (Figure 4a) using forcing data from 1965 (BCAL) resulted in a higher and more southward invasion of $C$. finmarchicus in two patches along the western and eastern coastlines, respectively, with up to 15 ind. $\mathrm{m}^{-3}$ in comparison with REF (Figures $13 \mathrm{~g}$ ). The lower seeding of $C$. finmarchicus at the entrance to North Sea in 2000s (Figure 4a) was probably related to a decline in the overwintering stock in the deep waters of the Norwegian Sea (Heath et al., 1999). For $C$. helgolandicus, abundance decreased with up to 15 ind. $\mathrm{m}^{-3}$ in both boundary areas (Figure $13 \mathrm{~h}$ ) because the inflow of warm SAW was weaker combined with a lower seeding compared 
to REF (Figure 4b). However, there was an increase in the central part of the northern boundary due to the higher inflow of ESAI. The seeding of warm-temperate species such as $C$. helgolandicus has been related to changes in the European shelf-edge current that has increased in strength since the 1980s (Beaugrand, 2004). The simulated changes in oceanic inflow increased the ratio of $C$. finmarchicus to Calanus spp. abundance from $40 \%$ in REF to $50 \%$ in BCAL (Figure 10). Changes in oceanic flow appeared more important in modifying the spatial distributions within the North Sea and less important for the relative Calanus species contribution.

Superimposed on the inflow trend, there has been an increase in sea-water temperatures since the 1960's and a change in the Calanus stock size that overwinters within the North Sea. C. finmarchicus is generally believed not to overwinter in the North Sea because it is too shallow (Beare et al., 2002; Fransz et al., 1991; Heath, 1999). Nevertheless, they were observed in relatively high numbers in the surface layer during winter in the northern part in the 1960's (Figure 4c). This higher overwintering expanded the spatial distribution southwards to $52^{\circ} \mathrm{N}$ in the western part for $C$. finmarchicus and increased abundances with up to 15 ind. $\mathrm{m}^{-3}$ according to INI (Figure 13c). It has been suggested that $C$. finmarchicus may overwinter in an atelo-diapause (i.e. low intensity diapause) in shelf seas instead of true diapause (Hirche, 1998). On the other hand, it is well known that $C$. helgolandicus overwinter in the North Sea since the 1980's probably due to warmer winters (Fransz et al., 1991). When using lower initial abundances (INI) according to the colder 1960s, C. helgolandicus decreased with up to 5 ind. $\mathrm{m}^{-3}$ abundance in most of the North Sea (Figure 13f). The lower temperature limit for growth is around $6^{\circ} \mathrm{C}$ in the model (Figure 3a). The present area-averaged temperatures in March ranges from 5.4 to $6.5^{\circ} \mathrm{C}$ (Figure 12a) and a $2^{\circ} \mathrm{C}$ lower temperatures is therefore detrimental for $C$. helgolandicus winter persistence in the North Sea. The ratio of $C$. finmarchicus to Calanus spp. abundance increased from $40 \%$ in REF to $66 \%$ in INI (Figure 10). Overwintering must be considered as an advantage for Calanus spp. because both species would be ready to utilise the spring bloom more efficiently and independently of the timing and spatial coverage of the oceanic inflow.

Temperature also changed the seasonal pattern of both Calanus species (Figures 12 c, d). At $2^{\circ} \mathrm{C}$ lower or higher temperatures, the first seasonal increase and peak-of-season were delayed or accelerated, respectively, two to three weeks. Lower temperatures were beneficial for both species during the late summer period. The 'growth-mortality' response to temperature is dome-shaped for both species but with different temperature optima (Figure 3b). The temperature response will therefore be either on the downhill or up-hill side of the 
response curve in the different areas and seasons dependent on temperature. For $C$. finmarchicus, lower temperatures caused higher abundances in the north-western part; whereas the opposite trend was found for $C$. helgolandicus (Figure 13a, b). Furthermore, $C$. helgolandicus increased in abundance in the central and north-eastern parts of the North Sea. Overall, temperature (-2T and $+2 \mathrm{~T})$ had a relatively small negative effect (1-2 percentage points) on the ratio of $C$. finmarchicus to Calanus spp. abundance (Figure 10). The model seems to suggest that the timing, and not the overall abundance, of Calanus spp. is particularly sensitive to temperature changes of $\pm 2^{\circ} \mathrm{C}$.

The scenario with combined effect of changes in inflow, initial abundances and lower temperatures (-2TIB ) showed the strongest response in abundances of $C$. finmarchicus, while C. helgolandicus mainly decreased in the boundary areas (Figures $13 \mathrm{i}, \mathrm{j}$ ). This scenario resulted in a ratio of $C$. finmarchicus to Calanus spp. of $72 \%$ that is in similar to the ratio based on CPR data of $81 \%( \pm 29 \% \mathrm{SE})$ (Figure 10). The seasonal patterns $\left(R^{2}=0.40-0.64\right)$ and model abundances $(M B=-22-40 \%)$ were also similar to CPR data from 1965 of both Calanus species (Table1). C. finmarchicus was present in the whole North Sea except from the German Bight and the English Channel (Figure 13k), whereas C. helgolandicus was found with highest numbers at the Dogger Bank and the northern and southern boundaries (Figure 13I). The agreement with the past patterns of population abundance and distribution gives further confidence in the model estimate including predictions of probable future scenarios', which is discussed in the next paragraphs.

\subsection{Calanus in a warmer North Sea}

In a warmer climate, the model predicts that plankton seasonality changes to an earlier occurrence of both Calanus species and an earlier termination of the spring phytoplankton bloom in the North Sea (Figure 12). Increasing temperature has previously been shown to increase heterotrophic grazing pressure on the spring phytoplankton bloom with implications for trophodynamics (Keller et al., 1999; Maar and Hansen, 2011; Müren et al., 2005). During the summer period, there was on the other hand no significant difference in phytoplankton biomass between scenarios. A previous model study also predicted small changes in summer

$471 \mathrm{Chl}$ a concentrations because the increased recycling of nutrients and primary production with 472 increasing temperature is counteracted by a higher grazing pressure (Maar and Hansen, 2011). 473 The peak-of-season of both Calanus species occurred two to three weeks earlier at $2^{\circ} \mathrm{C}$ higher temperatures (Figures 12b-c). Likewise, long-term time-series from the North Sea showed 
475 strong zooplankton phenology correlations with temperature where e.g. C. finmarchicus

476 occurred two to six weeks earlier at $2^{\circ} \mathrm{C}$ higher temperatures (Mackas et al., 2012). Larval fish

477 phenology responds in the same direction as zooplankton prey to higher temperatures, but the

478 changes tend to be smaller by a factor of two leading to increased mismatch in a warmer

479 ocean (Beaugrand et al., 2003; Mackas et al., 2012). Future climate change will probably also

480 change the hydrodynamics of the North Sea (Skogen et al., 2011). Model sensitivity studies

481 using predicted increases in air temperatures, short wave radiation and wind forcing resulted

482 in a stronger oceanic inflow, a smaller stratified area and a deeper mixed layer that would lead

483 to higher primary production in the North Sea (Skogen et al., 2011). However, this type of

484 scenario is constrained by the unknown changes in a future climate change situation, lack of

485 feed-back mechanisms from the ocean to the atmosphere and problems with downscaling of

486 climate forcing to regional levels (Skogen et al., 2011).

For the geographical distributions, populations of $C$. finmarchicus would mainly decrease in a warmer North Sea (Figure 13c). In contrast, C. helgolandicus populations are predicted to increase in the English Channel and the Fair Isle Channel and to decrease in the other areas (Figure 13d). The overall contribution of $C$. finmarchicus to Calanus spp. abundance (39\%) is therefore almost the same in $+2 \mathrm{~T}$ as in REF (Figure 10). Thus, although both species peak earlier (Figures 12c, d), the dome-shaped 'growth-mortality' response to temperature (Figure 3b) modify the summer abundances in a negative direction at temperatures $>12^{\circ} \mathrm{C}$ and $>14^{\circ} \mathrm{C}$ of $C$. finmarchicus and C. helgolandicus, respectively. parameterization of the mortality can have large implications for the model output

497 (Skarohamar et al., 2011). Mortality is assumed to be dependent on temperature because in warm seasons both predator activity and abundance are thought to be higher (Hirst et al., 2007). For Calanus, stage varying mortality has been observed with the highest mortality for eggs and non-feeding nauplii (Eiane and Ohman, 2004). Past and future changes in mortality are difficult to estimate, because other factors like cannibalism, parasitism and changes in the predator community also come into play (Eiane and Ohman, 2004; Neuheimer et al., 2009;

503 Speirs et al., 2006). The parameterization in the present model was chosen to be as simple as 504 possible and at the same time allow for changes in different scenarios, and is a combination of 505 temperature dependent mortality and intraguild predation by adult Calanus on eggs and non506 feeding nauplii. If intraguild predation is the most important part of the mortality on the zooplankton (Mitra, 2009), our projections may be reliable. 
Other uncertainties are the overwintering stock and the future inflow patterns since we do not know how those will change in a future warmer climate. However, it is likely that the overwintering population and oceanic inflow of $C$. finmarchicus in the North Sea would decline in a warmer future based on the trend in CPR data (Figures $4 c, d$ ), but this was not included in scenario $+2 T$. Hence, the future predictions of the two Calanus distributions must be considered with these uncertainties in mind. For $C$. finmarchicus, our predictions were nevertheless supported by ecological niche and eco-physiological models that indicate that populations at the southern edge of their distribution e.g. the North Sea would decline in a warmer climate (Helaouët et al., 2011; Reygondeau and Beaugrand, 2011a). Our results indicate that Calanus distributions cannot be extrapolated linearly with temperature due to the dome-shaped response of growth, changes in mortality and food availability. Moreover, for future modeling a better understanding of the control of the onset of and emergence from hibernation is needed.

The vertical distribution of both Calanus species was shown to deepen into cooler waters at higher temperatures, but still with $C$. helgolandicus located above $C$. finmarchicus (Figure 14). Other studies have shown that $C$. finmarchicus decreased in abundance with increasing water column stability in the North Atlantic Ocean (Beare et al., 2002; Reygondeau and Beaugrand, 2011a). These authors suggested that the decline of $C$. finmarchicus was due to food limitation and temperature effects. Water column stratification is expected to increase with higher temperatures and suggested to displace the distribution of $C$. finmarchicus further north in the North Atlantic Ocean (Reygondeau and Beaugrand, 2011b). In the North Sea, $C$. finmarchicus not only exploits the spring bloom, but also the food availability in the summer DCM in stratified areas (Jónasdóttir and Koski, 2011). Ecosystem modeling, on the other hand, suggests that future higher temperatures combined with more wind would result in a smaller stratified area and a deeper mixed layer in the North Sea (Skogen et al., 2011). This effect will reduce the occurrences of DCM that may be detrimental for $C$. finmarchicus growth during summer. Thus, future predictions are difficult to make and the found non-linear interactions of Calanus spp. with various environmental parameters are complicated to resolve. Models, such as the present, are therefore very useful tools to address this challenge.

\subsection{Model validation} validated against CPR data since it is the most comprehensive data set for the North Sea. 
541 Abundances were compared as monthly means for the CPR standard areas in order to

542 subsume small-scale patchiness due to zooplankton behavioural responses to environmental

543 factors, local weather conditions and counting procedures (Richardson et al., 2006). The model

544 succeeded to reproduce the overall seasonal $\left(R^{2}=0.68\right.$ to 0.89$)$ and spatial ( $\mathrm{MB}=-22$ to $\left.-11 \%\right)$

545 patterns of both Calanus species in 2005 (Figures 8 and 9). CPR data has previously been used

546 to validate bulk zooplankton biomass in the North Sea (Broekhuizen et al., 1995) and was

547 found useful to assess future model developments in order to reduce errors and improve

548 model fit. CPR data has been criticised for underestimating the abundance of certain species,

549 for not being depth-resolved and not to cover all areas and months equally (Broekhuizen et al.,

550 1995). We tried to accommodate these issues by using CPR correction factors for under-

551 sampling (Pitois and Fox, 2006) and to compare model results with another data set from

552 north of the Dogger Bank (Figures 1, 11). Model data was here compared with depth resolved

553 distributions of Calanus spp. in summer 2005 (Jónasdóttir and Koski, 2011). The model

554 captured the main patterns with $C$. helgolandicus located in the warm surface layer and $C$.

555 finmarchicus located around the thermocline at 25 to $40 \mathrm{~m}$ depth (Figure 11). However, the

556 observed pronounced peak at $15 \mathrm{~m}$ depth of $C$. helgolandicus was not reproduced by the

557 model. The peak at $15 \mathrm{~m}$ did not coincide with the DCM and temperatures were similar in the

558 upper mixed layer. It is therefore unknown from the current data set what caused this peak,

559 but it could be related to mortality, other prey types or small-scale horizontal or vertical

560 transport. The vertical distributions were given as relative values of total water column

561 abundance because the model values were one order of magnitude lower than observations.

562 Since the model was in agreement with CPR data, this shows that different data sets such as

563 CPR and net samples can give very different results probably because of small-scale patchiness

564 and very different sampling procedures. Nevertheless, the model reproduced the vertical

565 patterns observed during summer (Figure 11), where $C$. finmarchicus retreat to deeper and

566 cooler layers to feed on the deep Chl $a$ maximum (Jónasdóttir and Koski, 2011).

567 The simulated relative frequency with temperature of the two Calanus species shows

568 that Calanus does only really appear when the temperature is above $6^{\circ} \mathrm{C}$ in the North Sea and

569 they both peak at app. 11 to $16^{\circ} \mathrm{C}$ (Figure 7). In the North Atlantic, the distribution shows a

570 similar pattern for $C$. helgolandicus with maximum presence at 13 to $17^{\circ} \mathrm{C}$ (Bonnet et al.,

571 2005). C. finmarchicus on the other hand are found in high numbers at temperatures from 0

572 to $10^{\circ} \mathrm{C}$ followed by a decrease until $18^{\circ} \mathrm{C}$ in the North Atlantic Ocean (Bonnet et al., 2005). The

573 thermal niche in the North Sea is the result of both the effect of temperature on growth and

574 mortality (Figure 3), population dynamics of Calanus, oceanic inflow, the seasonality of the 
575 prey and the present temperatures that mainly are within 4 to $22^{\circ} \mathrm{C}$ (Figure 7). Thus, although

576 C. finmarchicus can evidently thrive at lower temperatures (Swalethorp et al., 2011) it does not

577 appear so from the relative distribution in the North Sea in contrast to studies covering a

578 larger temperature span (Bonnet et al., 2005; Helaouët and Beaugrand, 2007).

579 4.4. Zooplankton prey fields to fish larvae models

580

In order to understand how climate variability influences fish recruitment, individualbased models (IBMs) have recently been applied to key fish species (Christensen et al., 2007; Fiksen et al., 2007). These models can be used to examine transport dynamics, survival and growth of fish larvae and to identify critical habitats (Hinrichsen et al., 2005; Kühn et al., 2008; Lough et al., 2005). If vital rates of fish are to be examined, the IBMs also need information of prey fields that can be obtained from measurements or ecosystem modelling. Monitoring provides data on vertical and horizontal species distributions. However, extrapolation of point sources vertically, horizontally and seasonally is presumably associated with an unknown error and should therefore be used with caution.

Alternatively, ecosystem models can provide 3D zooplankton prey fields with a high temporal and spatial resolution. However, they often consider bulk estimates without speciesor size specific resolution that are crucial for feeding of fish larvae (Munk, 1997). Copepods undergo important ontogenetic change in size that reach an order of 100 through their life cycle from eggs to adults (Carlotti et al., 1993). In addition, there is a huge variation in size between copepod species from approximately $0.1 \mathrm{~mm}$ of e.g. Oithona spp. up to several $\mathrm{mm}$ for adult Calanus spp. (Nielsen and Munk, 1998). Another solution is to model key species of zooplankton as life-stages coupled to 3D hydrodynamic - biogeochemical models. This has previously been applied for C. finmarchicus in the North Atlantic Ocean (Bryant et al., 1997;

598 Heath et al., 1997; Maps et al., 2010; Speirs et al., 2006) and C. helgolandicus in the northern

599 North Sea (Heath et al., 1997). The approach of using life-stage models has, however, been

600 criticized for unrealistic ingestion of phytoplankton, lack of boundary data and increase in model complexity (Daewel et al., 2008). On the other hand, the advantage is that life-stage models coupled to ecosystem models provide high temporal-spatial resolution prey fields of size-structured key species that is directly coupled to climate forcing. The modeled spatial patterns of the two Calanus species were quite different from that of the bulk mesozooplankton (Figures $6 \mathrm{~d}-\mathrm{f}$ ) and thus provide more detailed information of the 
607 providing realistic 3D life-stage specific prey fields of Calanus spp. in the North Sea as input to 608 fish larvae models. 
This study was supported by grants from the Directorate for Food, Fisheries and Agri

611 Business: Modelling the Impact of Hydrography and Lower Trophic Production on Fish

612 Recruitment (MODREC, Contract no. 3304-FVFP-060683), the Danish Strategic Research

613 Council: Sustainable fisheries, climate change and the North Sea ecosystem (SUNFISH, Contract

614 no. 2101-07-0080) and from the EU: Marine Ecosystem Evolution in a Changing Environment

615 (MEECE, FP7-ENV-2007, Grant Agreement no. 212085) and Vectors of Change in Oceans and

616 Seas, Marine Life, Impact and Economic Sectors (Vectors, FP7-Ocean-2010, Grant Agreement

617 no. 266445). We would also like to thank Sir Alister Hardy Foundation for Ocean Science

618 (SAHFOS) for their associated researcher bursary to ZG during 2010 and providing data from

619 the Continuous Plankton Recorder (CPR) surveys that are utilized in this study, David Johns at

620 SAHFOS for his correspondence about the CPR data and Darren Stevens at SAHFOS for

621 extracting the CPR data. We thank Dr. Tone Falkenhaug, Institute of Marine Research, Norway,

622 for providing data on Calanus from the Arendal station. Finally, we thank two anonymous

623 referees for giving constructive suggestions for improvement of a previous version of the MS.

624

625

626

627

628

629

630

631 
634

635

636

637

638

639

640

641

642

643

644

645

646

647

648

649

650

651

652

653

654

655

656

657

658

659

660

661

662

663

664

665

666

667

668

669

670

671

672

Arnott, S.A. Ruxton, G.D., 2002. Sandeel recruitment in the North Sea: demographic, climatic and trophic effects. Marine Ecology Progress Series 238, 199-210.

Beare, D.J., Batten, S., Edwards, M., Reid, D.G., 2002. Prevalence of boreal Atlantic, temperate Atlantic and neritic zooplankton in the North Sea between 1958 and 1998 in relation to temperature, salinity, stratification intensity and Atlantic inflow. Journal of Sea Research 48, 29-49.

Beare, D.J. McKenzie, E., 1999. Temporal patterns in the surface abundance of Calanus finmarchicus and C. helgolandicus in the northern North Sea (1958-1996) inferred from Continuous Plankton Recorder data. Marine Ecology Progress Series 190, 241-251.

Beaugrand, G., 2004. The North Sea regime shift: evidence, causes, mechanisms and consequences. Progress in Oceanography 60, 245-262.

Beaugrand, G., Brander, K.M., Lindley, J.A., Souissi, S., Reid, P.C., 2003. Plankton effect on cod recruitment in the North Sea. Nature 426, 661-664.

Beaugrand, G., Ibanez, F., Lindley, J.A., Reid, P.C., 2002. Diversity of calanoid copepods in the North Atlantic and adjacent seas: species associations and biogeography. Marine Ecology Progress Series 232, 179-195.

Beaugrand, G. Reid, P.C., 2003. Long-term changes in phytoplankton, zooplankton and salmon related to climate. Global Change Biology 9, 801-817.

Bonnet, D., Richardson, A., Harris, R., Hirst, A., Beaugrand, G., Edwards, M., Ceballos, S., Diekman, R., Lopez-Urrutia, A., Valdes, L., Carlotti, F., Molinero, J.C., Weikert, H., Greve, W., Lucic, D., Albaina, A., Yahia, N.D., Umani, S.F., Miranda, A., dos Santos, A., Cook, K., Robinson, S., de Puelles, M.L.F., 2005. An overview of Calanus helgolandicus ecology in European waters. Progress in Oceanography 65, 1-53.

Brey, T., 2001. Population dynamics in benthic invertebrates. A virtual handbook. http://www.thomasbrey.de/science/virtualhandbook/navlog/index.html

Broekhuizen, N., Heath, M.R., Hay, S.J., Gurney, W.S.C., 1995. Modeling the Dynamics of the North-Sea Mesozooplankton. Netherlands Journal of Sea Research 33, 381-406.

Bryant, A.D., Heath, M., Gurney, W.S.G., Beare, D.J., Robertson, W., 1997. The seasonal dynamics of Calanus finmarchicus: development of a three-dimensional structured population model and application to the northern North Sea. Journal of Sea Research 38, 361-379.

Burrows, M.T., schoeman, D.S., Buckley, L.B., Moore, P., Poloczanska, E.S., Brander, K.M., Brown, C., Bruno, J.F., Duarte, C.M., Halpern, B.S., Holding, J., Kappel, C.V., Kiessling, W., O'Connor, M.I., Pandolfi, J.M., Parmesan, C., Schwing, F.B., Sydeman, W.J., Richardson, A.J., 2011. The Pace of Shifting Climate in Marine and Terrestrial Ecosystems. Science 334, 652-655.

Carlotti, F., Krause, M., Radach, G., 1993. Growth and Development of Calanus finmarchicus Related to the Influence of Temperature - Experimental Results and Conceptual-Model. Limnology and Oceanography 38, 1125-1134.

Christensen, A., Daewel, U., Jensen, H., Mosegaard, H., St John, M., Schrum, C., 2007. Hydrodynamic backtracking of fish larvae by individual-based modelling. Marine Ecology Progress Series 347, 221-232. 
Daewel, U., Peck, M.A., Schrum, C., St John, M.A., 2008. How best to include the effects of climatedriven forcing on prey fields in larval fish individual-based models. Journal of Plankton Research $30,1-5$.

Durant, J.M., Hjermann, D.O., Anker-Nilssen, T., Beaugrand, G., Mysterud, A., Pettorelli, N., Stenseth, N.C., 2005. Timing and abundance as key mechanisms affecting trophic interactions in variable environments. Ecology Letters 8, 952-958.

Eiane, K. Ohman, M.D., 2004. Stage-specific mortality of Calanus finmarchicus, Pseudocalanus elongatus and Oithona similis on Fladen Ground, North Sea, during a spring bloom. Marine Ecology Progress Series 268, 183-193.

Fennel, W., 2001. Modeling of copepods with links to circulation models. Journal of Plankton Research 23, 1217-1232.

Fiksen, O., Jørgensen, C., Kristiansen, T., Vikebo, F., Huse, G., 2007. Linking behavioural ecology and oceanography: larval behaviour determines growth, mortality and dispersal. Marine Ecology Progress Series 347, 195-205.

Fransz, H.G., Colebrook, J.M., Gamble, J.C., Krause, M., 1991. The zooplankton of the North-Sea. Netherlands Journal of Sea Research 28, 1-52.

Gaard, E. Reinert, J., 2002. Pelagic cod and haddock juveniles on the Faroe plateau: distribution, diets and feeding habitats, 1994-1996. Sarsia 87, 193-206.

Gislason, A. Astthorsson, A.S., 2002. The food of Norwegian spring-spawning herring in the western Norwegian Sea in relation to the annual cycle of zooplankton. Sarsia 87, 236-247.

Hansen, P.J., Bjørnsen, P.K., Hansen, B.W., 1997. Zooplankton grazing and growth: Scaling within the 22,000- $\mu \mathrm{m}$ body size range. Limnology and Oceanography 42, 687-704.

Harris, R.P., Wiebe, P.H., Lenz, M., Skjoldal, E.F., Huntley, M.E., 2000. ICES zooplankton methodology manual.

Heath, M., Robertson, W., Mardaljevic, J., Gurney, W.S.G., 1997. Modelling the population dynamics of Calanus in the Fair Isle Current off northern Scotland. Journal of Sea Research 38, 381-412.

Heath, M.R., 1999. The ascent migration of Calanus finmarchicus from overwintering depths in the Faroe-Shetland Channel. Fisheries Oceanography 8, 84-99.

Heath, M.R., 2007. The consumption of zooplankton by early life stages of fish in the North Sea. ICES Journal of Marine Science 64, 1650-1663.

Heath, M.R., Backhaus, J.O., Richardson, K., McKenzie, E., Slagstad, D., Beare, D., Dunn, J., Fraser, J.G., Gallego, A., Hainbucher, D., Hay, S., Jonasdottir, S., Madden, H., Mardaljevic, J., Schacht, A., 1999. Climate fluctuations and the spring invasion of the North Sea by Calanus finmarchicus. Fisheries Oceanography 8, 163-176.

Helaouët, P. Beaugrand, G., 2007. Macroecology of Calanus finmarchicus and C. helgolandicus in the North Atlantic Ocean and adjacent seas. Marine Ecology Progress Series 345, 147-165.

Helaouët, P., Beaugrand, G., Reid, P.C., 2011. Macrophysiology of Calanus finmarchicus in the North Atlantic Ocean. Progress in Oceanography 91, 217-228.

Hinrichsen, H.H., Schmidt, J.O., Petereit, C., Mollmann, C., 2005. Survival probability of Baltic larval cod in relation to spatial overlap patterns with their prey obtained from drift model studies. ICES Journal of Marine Science 62, 878-885. 
Hirche, H.J., 1998. Dormancy in three Calanus species (C. finmarchicus, C. glacialis and C.hyperborecus) from the North Atlantic. Archiv Fur Hydrobiologie 52, 359-369.

Hirst, A.G., Bonnet, D., Harris, R.P., 2007. Seasonal dynamics Calanus helgolandicus and mortality rates of over two years at a station in the English Channel. Marine Ecology Progress Series 340, 189205.

Hjøllo, S.S., Huse, G., Skogen, M., Melle, W., 2012. Modelling secondary production in the Norwegian Sea with a fully coupled physical/primary production/individual-based Calanus finmarchicus model system. Marine Biology Research 8, 508-526.

Hjøllo, S.S., Skogen, M.D., Svendsen, E., 2009. Exploring currents and heat within the North Sea using a numerical model. Journal of Marine Systems 78, 180-192.

Johns, D., 2009. Monthly averaged data for zoopankton (48-63N, 10W-12E) 1946-2007 as recorded by the Continuous Plankton Recorder. Sir Alister Hardy Foundation for Ocean Science, Plymouth, UK.

Jónasdóttir, S.H. Koski, M., 2011. Biological processes in the North Sea: comparison of Calanus helgolandicus and Calanus finmarchicus vertical distribution and production. Journal of Plankton Research 33, 85-103.

Jónasdóttir, S.H., Trung, N.H., Hansen, F., Gartner, S., 2005. Egg production and hatching success in the calanoid copepods Calanus helgolandicus and Calanus finmarchicus in the North Sea from March to September 2001. Journal of Plankton Research 27, 1239-1259.

Keller, A.A., Oviatt, C.A., Walker, H.A., Hawk, J.D., 1999. Predicted impacts of elevated temperature on the magnitude of the winter-spring phytoplankton bloom in temperate coastal waters: $\mathrm{A}$ mesocosm study. Limnology and Oceanography 44, 344-356.

Kühn, W., Peck, M.A., Hinrichsen, H.H., Daewel, U., Moll, A., Pohlmann, T., Stegert, C., Tamm, S., 2008. Defining habitats suitable for larval fish in the German Bight (southern North Sea): An IBM approach using spatially- and temporally-resolved, size-structured prey fields. Journal of Marine Systems 74, 329-342.

Larsen, J., Hoyer, J.L., She, J., 2007. Validation of a hybrid optimal interpolation and Kalman filter scheme for sea surface temperature assimilation. Journal of Marine Systems 65, 122-133.

Lough, R.G., Buckley, L.J., Werner, F.E., Quinlan, J.A., Edwards, K.P., 2005. A general biophysical model of larval cod (Gadus morhua) growth applied to populations on Georges Bank. Fisheries Oceanography 14, 241-262.

Maar, M. Hansen, J.L.S., 2011. Increasing temperatures change pelagic trophodynamics and the balance between pelagic and benthic secondary production in a water column model of the Kattegat. Journal of Marine Systems 85, 57-70.

Maar, M., Møller, E.F., Larsen, J., Madsen, K.S., Wan, Z.W., She, J., Jonasson, L., Neumann, T., 2011. Ecosystem modelling across a salinity gradient from the North Sea to the Baltic Sea. Ecological Modelling 222, 1696-1711.

Maar, M., Nielsen, T.G., Gooding, S., Tönnesson, K., Tiselius, P., Zervoudaki, S., Christou, E., Sell, A., Richardson, K., 2004. Trophodynamic function of copepods, appendicularians and protozooplankton in the late summer zooplankton community in the Skagerrak. Marine Biology $144,917-933$.

Mackas, D.L., Greve, W., Edwards, M., Chiba, S., Tadokoro, K., Eloire, D., Mazzocchi, M.G., Batten, S., Richardson, A.J., Johnson, C., Head, E., Conversi, A., Peluso, T., 2012. Changing zooplankton 
seasonality in a changing ocean: Comparing time series of zooplankton phenology. Progress in Oceanography 97, 31-62.

Mackinson, S. Daskalov, G., 2007. An Ecosystem Model of the North Sea to support an ecosystem approach to fisheries management: description and parameterisation. Science Series. Technical Report 142,

Maps, F., Plourde, S., Zakardjian, B., 2010. Control of dormancy by lipid metabolism in Calanus finmarchicus: a population model test. Marine Ecology Progress Series 403, 165-180.

Mitra, A., 2009. Are closure terms appropriate or necessary descriptors of zooplankton loss in nutrientphytoplankton-zooplankton type models? Ecological Modelling 220, 611-620.

Møller, E.F., Maar, M., Jonasdottir, S.H., Nielsen, T.G., Tonnesson, K., 2012. The effect of changes in temperature and food on the development of Calanus finmarchicus and Calanus helgolandicus populations. Limnology and Oceanography 57, 211-220.

Munk, P., 1992. Foraging Behavior and Prey Size Spectra of Larval Herring Clupea-Harengus. Marine Ecology-Progress Series 80, 149-158.

Munk, P., 1997. Prey size spectra and prey availability of larval and small juvenile cod. Journal of Fish Biology 51, 340-351.

Munk, P. Nielsen, T.G., 1994. Trophodynamics of the plankton community at Dogger Bank - predatory impact by larval fish. Journal of Plankton Research 16, 1225-1245.

Müren, U., Berglund, J., Samuelsson, K., Andersson, A., 2005. Potential effects of elevated sea-water temperature on pelagic food webs. Hydrobiologia 545, 153-166.

Neuheimer, A.B., Gentleman, W.C., Galloway, C.L., Johnson, C.L., 2009. Modeling larval Calanus finmarchicus on Georges Bank: time-varying mortality rates and a cannibalism hypothesis. Fisheries Oceanography 18, 147-160.

Neumann, T., 2000. Towards a 3D-ecosystem model of the Baltic Sea. Journal of Marine Systems 25, 405-419.

Neumann, T. Schernewski, G., 2008. Eutrophication in the Baltic Sea and shifts in nitrogen fixation analyzed with a 3D ecosystem model. Journal of Marine Systems 74, 592-602.

Nielsen, T.G. Munk, P., 1998. Zooplankton diversity and the predatory impact by larval and small juvenile fish at the Fisher Banks in the North Sea. Journal of Plankton Research 20, 2313-2332.

Payne, M.R., Hatfield, E.M.C., Dickey-Collas, M., Falkenhaug, T., Gallego, A., Groger, J., Licandro, P., Llope, M., Munk, P., Rockmann, C., Schmidt, J.O., Nash, R.D.M., 2009. Recruitment in a changing environment: the 2000s North Sea herring recruitment failure. ICES Journal of Marine Science 66, 272-277.

Philippart, C.J.M., Anadon, R., Danovaro, R., Dippner, J.W., Drinkwater, K.F., Hawkins, S.J., O'Sullivan, G., Oguz, T., Reid, P.C., 2007. Climate change impacts on the European marine and coastal environment. Ecosystems Approach. Position paper 9, Marine Board-European Science Foundation, Strasbourg.

Pitois, S.G. Fox, C.J., 2006. Long-term changes in zooplankton biomass concentration and mean size over the Northwest European shelf inferred from Continuous Plankton Recorder data. ICES Journal of Marine Science 63, 785-798. 
Planque, B. Fromentin, J.M., 1996. Calanus and environment in the eastern North Atlantic .1. Spatial and temporal patterns of $C$. finmarchicus and C. helgolandicus. Marine Ecology Progress Series 134, 101-109.

Reid, P.C., Edwards, M., Beaugrand, G., Skogen, M., Stevens, D., 2003. Periodic changes in the zooplankton of the North Sea during the twentieth century linked to oceanic inflow. Fisheries Oceanography 12, 260-269.

Reygondeau, G. Beaugrand, G., 2011a. Future climate-driven shifts in distribution of Calanus finmarchicus. Global Change Biology 17, 756-766.

Reygondeau, G. Beaugrand, G., 2011b. Water column stability and Calanus finmarchicus. Journal of Plankton Research 33, 119-136.

Richardson, A.J., Walne, A.W., John, A.W.G., Jonas, T.D., Lindley, J.A., Sims, D.W., Stevens, D., Witt, M., 2006. Using continuous plankton recorder data. Progress in Oceanography 68, 27-74.

Ringuette, M., Castonguay, M., Runge, J.A., Gregoire, F., 2002. Atlantic mackerel (Scomber scombrus) recruitment fluctuations in relation to copepod production and juvenile growth. Canadian Journal of Fisheries and Aquatic Sciences 59, 646-656.

Sass, B.H., Nielsen, N.W., Jørgensen, J.U., Amstrup, B., Kmit, M., Mogensen, K.S., 2002. The operational DMI-HIRLAM model System-2002 version. DMI Technical Reports 02-05, Danish Meteorological Institute, Copenhagen.

She, J., Berg, P., Berg, J., 2007. Bathymetry impacts on water exchange modelling through the Danish Straits. Journal of Marine Systems 65, 450-459.

Skarohamar, J., Reigstad, M., Carroll, J., Eiane, K., Riser, C.W., Slagstad, D., 2011. Effects of mortality changes on biomass and production in Calanus spp. populations. Aquatic Biology 12, 129-145.

Skogen, M.D., Drinkwater, K., Hjøllo, S.S., Schrum, C., 2011. North Sea sensitivity to atmospheric forcing. Journal of Marine Systems 85, 106-114.

Speirs, D.C., Gurney, W.S.C., Heath, M.R., Horbelt, W., Wood, S.N., de Cuevas, B.A., 2006. Ocean-scale modelling of the distribution, abundance, and seasonal dynamics of the copepod Calanus finmarchicus. Marine Ecology Progress Series 313, 173-192.

Stegert, C., Kreus, M., Carlotti, F., Moll, A., 2007. Parameterisation of a zooplankton population model for Pseudocalanus elongatus using stage durations from laboratory experiments. Ecological Modelling 206, 213-230.

Stegert, C., Moll, A., Kreus, M., 2009. Validation of the three-dimensional ECOHAM model in the German Bight for 2004 including population dynamics of Pseudocalanus elongatus. Journal of Sea Research 62, 1-15.

Swalethorp, R., Kjellerup, S., Dunweber, M., Nielsen, T.G., Møller, E.F., Rysgaard, S., Hansen, B.W., 2011. Grazing, egg production, and biochemical evidence of differences in the life strategies of Calanus finmarchicus, C. glacialis and C. hyperboreus in Disko Bay, western Greenland. Marine Ecology-Progress Series 429, 125-144.

van Deurs, M., van Hal, R., Tomczak, M.T., Jonasdottir, S.H., Dolmer, P., 2009. Recruitment of lesser sandeel Ammodytes marinus in relation to density dependence and zooplankton composition. Marine Ecology Progress Series 381, 249-258.

Williams, R. Conway, D.V.P., 1988. Vertical-Distribution and Seasonal Numerical Abundance of the Calanidae in Oceanic Waters to the Southwest of the British-Isles. Hydrobiologia 167, 259-266. 


\section{Figure captions}

Figure 1. The NE Atlantic Ocean showing the location of the North Sea and below a detailed map of the North Sea with water depths $>110 \mathrm{~m}$ indicated with light grey. The sampling stations 1, 3 and 5 north of Dogger Bank and Arendal St. in the Skagerrak are shown as black circles. CPR data points show where $C$. finmarchicus and $C$. helgolandicus are present within the CPR standard areas B1, B2, C1, C2, D1, D2 and D3 in 2005. Area C1 was reduced in the northern part and $D 3$ in the eastern part to eliminate subareas with no data coverage.

Figure 2. Diagram of the stage - structured model adapted to Calanus spp. describing the development of 5 stages from 'eggs-NII' up to 'adults' (black boxes). Adult females lay eggs and the first stage ('eggs-N2') is non-feeding and hatching into nauplii stage 'N3-N6' depends on temperature. The stages are coupled to ERGOM through ingestion of phytoplankton and microzooplankton, egestion, respiration, excretion and predation mortality (grey boxes). EggsN2 can also be ingested by adults.

Figure 3. Temperature response of A) growth, mortality and B) 'growth-mortality' of adult $C$. finmarchicus and $C$. helgolandicus in units per day of the population biomass.

Figure 4. Annual average $( \pm S E)$ of $C P R$ abundances at the model boundaries in areas $B 1, B 2$ and D3 from five periods of A) C. finmarchicus and B) $C$. helgolandicus and January values in the CPR standard areas of C) $C$. finmarchicus and D) $C$. helgolandicus from two time periods.

Figure 5. Model and monitoring data from the Arendal Station of A) C. finmarchicus $C 5$ and adults and B) C. helgolandicus C5 and adults in 2005. Note the different scales on y-axis.

Figure 6. Annual average of A) temperature $\left.\left({ }^{\circ} \mathrm{C}\right), \mathrm{B}\right) \mathrm{Chl} a$ concentrations $\left.\left(\mathrm{mg} \mathrm{m}^{-3}\right), \mathrm{C}\right)$

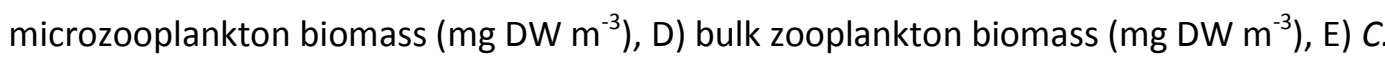
finmarchicus $\mathrm{C} 4$ to adult abundance (ind. $\mathrm{m}^{-3}$ ) on log-scale and F) C. helgolandicus $\mathrm{C} 4$ to adult abundance (ind. $\mathrm{m}^{-3}$ ) on log-scale at $10 \mathrm{~m}$ depth in REF.

Figure 7. The relative frequency of surface temperatures and abundances of $C$. finmarchicus and $C$. helgolandicus nauplii to adults from March to October.

Figure 8. Model comparison of abundances of copepodite stages ' $\mathrm{C} 5$ to adults' with CPR data of ' $C 4$ to adults' of $C$. finmarchicus (ind. $\mathrm{m}^{-3}$ ) for the seven standard areas in the North Sea in 2005. Percentage model bias (\%MB) is shown for each area. The MB of the seasonal distributions using monthly means and the seasonal correlation using 'log +1 ' transformed monthly means between model and CPR data are shown in the last figure.

Figure 9. Model comparison of abundances of copepodite stages ' $\mathrm{C} 5$ to adults' with $\mathrm{CPR}$ data of ' $\mathrm{C} 4$ to adults' of $C$. helgolandicus abundance (ind. $\mathrm{m}^{-3}$ ) for the seven standard areas in the North Sea in 2005. Percentage model bias (\%MB) is shown for each area. The MB of the seasonal distributions using monthly means and the seasonal correlation using 'log +1 ' transformed monthly means between model and CPR data are shown in the last figure. 
Figure 10. Annual ratio (\%) of $C$. finmarchicus to Calanus spp. abundance (10 $\mathrm{m}$ depth) in the North Sea for the different model scenarios and of CPR data for REF and -2TIB.

Figure 11. Comparison of vertical profiles from field data (symbols) and model data (lines) of A) temperature, B) Chl a concentrations, and relative adult abundance to total water column abundance of C) C. finmarchicus and D) C. helgolandicus north of Dogger Bank averaged over the period 27 July-2 August 2005. Data was redrawn from Jónasdóttir and Koski (2011).

891

892 Figure 12. Area-averaged A) Surface temperatures for REF, B) Chl $a$ concentrations, C) $C$.

893 finmarchicus abundance and $\mathrm{D}) \mathrm{C}$. helgolandicus abundance for REF, $-2 \mathrm{~T}$ and $+2 \mathrm{~T}$ scenarios

894 from March to October.

895

896

Figure 13. A-J) Difference in abundance of $C 4$ to adults of $C$. finmarchicus and $C$. helgolandicus between the scenarios $(-2 \mathrm{~T},+2 \mathrm{~T}, \mathrm{INI}, \mathrm{BCAL}$ and $-2 \mathrm{TIB})$ and REF and $\mathrm{K}-\mathrm{L})$ abundance of $\mathrm{C} 4$ to adults of $C$. finmarchicus and $C$. helgolandicus in scenario -2TIB from March to October.

899

900 Figure 14. Vertical profiles of adults of A) C. finmarchicus and B) C. helgolandicus in REF, -2T and $+2 T$ scenarios north of Dogger Bank (St. 5) from 27 July to 2 August.

902 
Table 1. Statistics of the model correlation (monthly means, $p<0.05$ ) and model bias (annual means) between 1) model calibration and CPR data from 2004 and 2) model scenario -2TIB and CPR data from 1965, where $n$ is the number of data pairs in the analysis. CPR data of $C$. finmarchicus in area D3 was ignored due to their absence.

\begin{tabular}{|ccccc|}
\hline Statistics & Species & $\begin{array}{c}\text { Calibration } \\
\text { values }\end{array}$ & $\begin{array}{c}-2 \text { TIB } \\
\text { values }\end{array}$ & $n$ \\
\hline MB & C. finmarchicus & 57 & -22 & 6 \\
& C. helgolandicus & -5 & 40 & 7 \\
$R^{2}$ & C. finmarchicus & 0.64 & 0.40 & 12 \\
& C. helgolandicus & 0.40 & 0.64 & 12 \\
\hline
\end{tabular}


Table 2. Description of model scenarios where '-' is no change and ' + ' is a change in comparison with REF. $\mathrm{T}=$ temperature, $\mathrm{INI}=$ initial abundance, $\mathrm{BCAL}=$ boundary condition of Calanus.

\begin{tabular}{|c|c|c|c|c|c|}
\hline$\#$ & abbreviation & Temperature & Initial values & Oceanic inflow & Description \\
\hline 1 & REF & - & - & - & Reference year 2005 \\
\hline 2 & $-2 T$ & $-2^{\circ} \mathrm{C}$ & - & - & Cold year \\
\hline 3 & $+2 \mathrm{~T}$ & $+2^{\circ} \mathrm{C}$ & - & - & Warm year \\
\hline 4 & INI & - & + & - & $\begin{array}{l}\text { Initial abundance } \\
\text { according to } 1960 \text { 's }\end{array}$ \\
\hline 5 & BCAL & - & - & + & Inflow 1965 \\
\hline 6 & $-2 \mathrm{TIB}$ & $-2^{\circ} \mathrm{C}$ & + & + & $\begin{array}{l}\text { Cold year + initial + } \\
\quad \text { inflow } 1965\end{array}$ \\
\hline
\end{tabular}


Figure 1
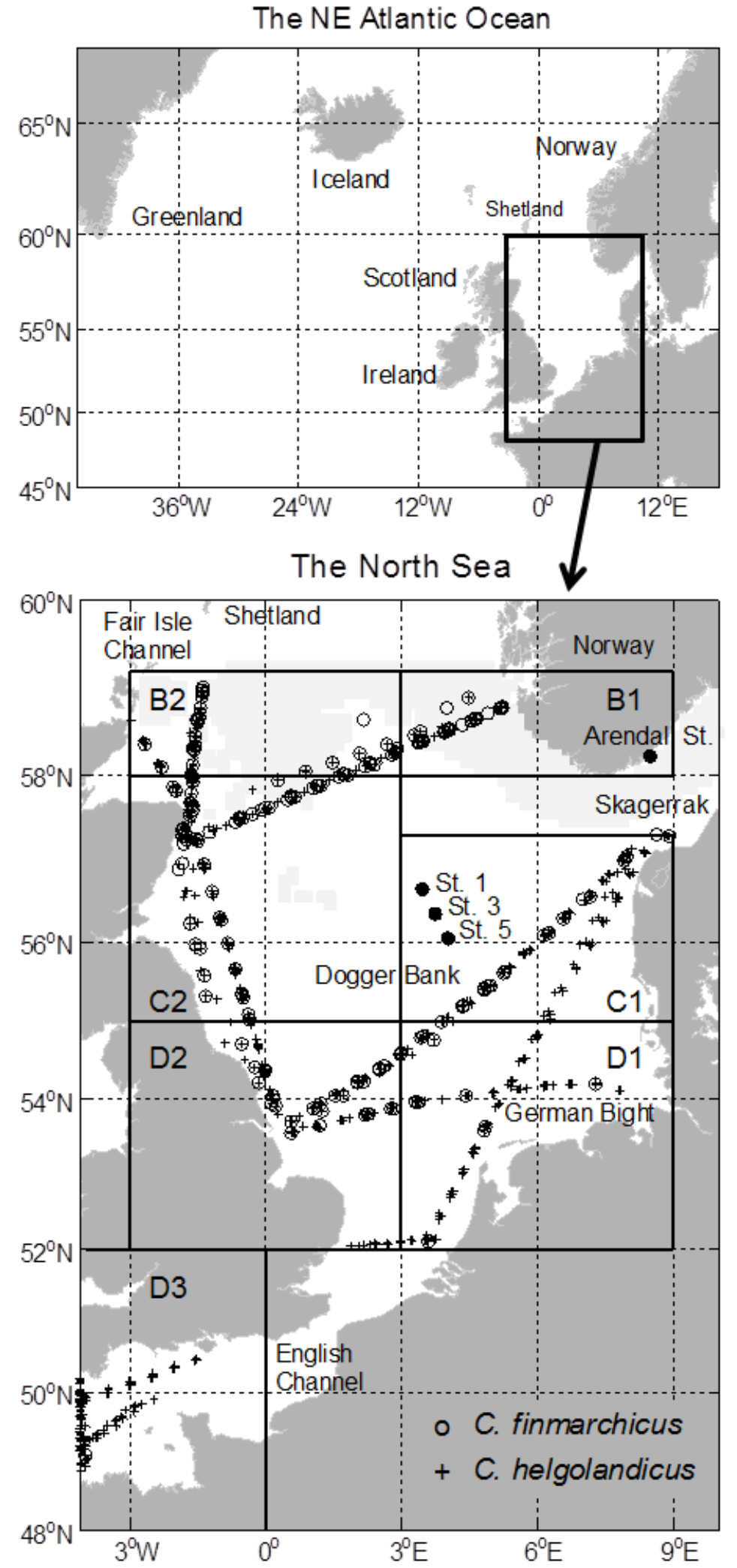


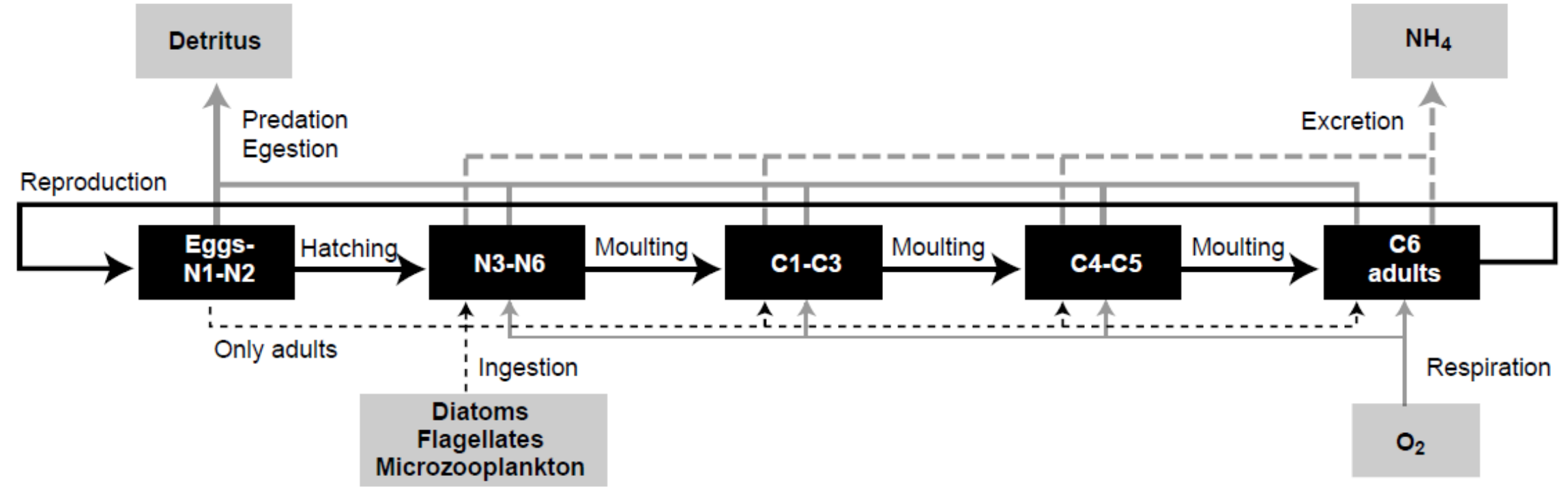


Figure 3.
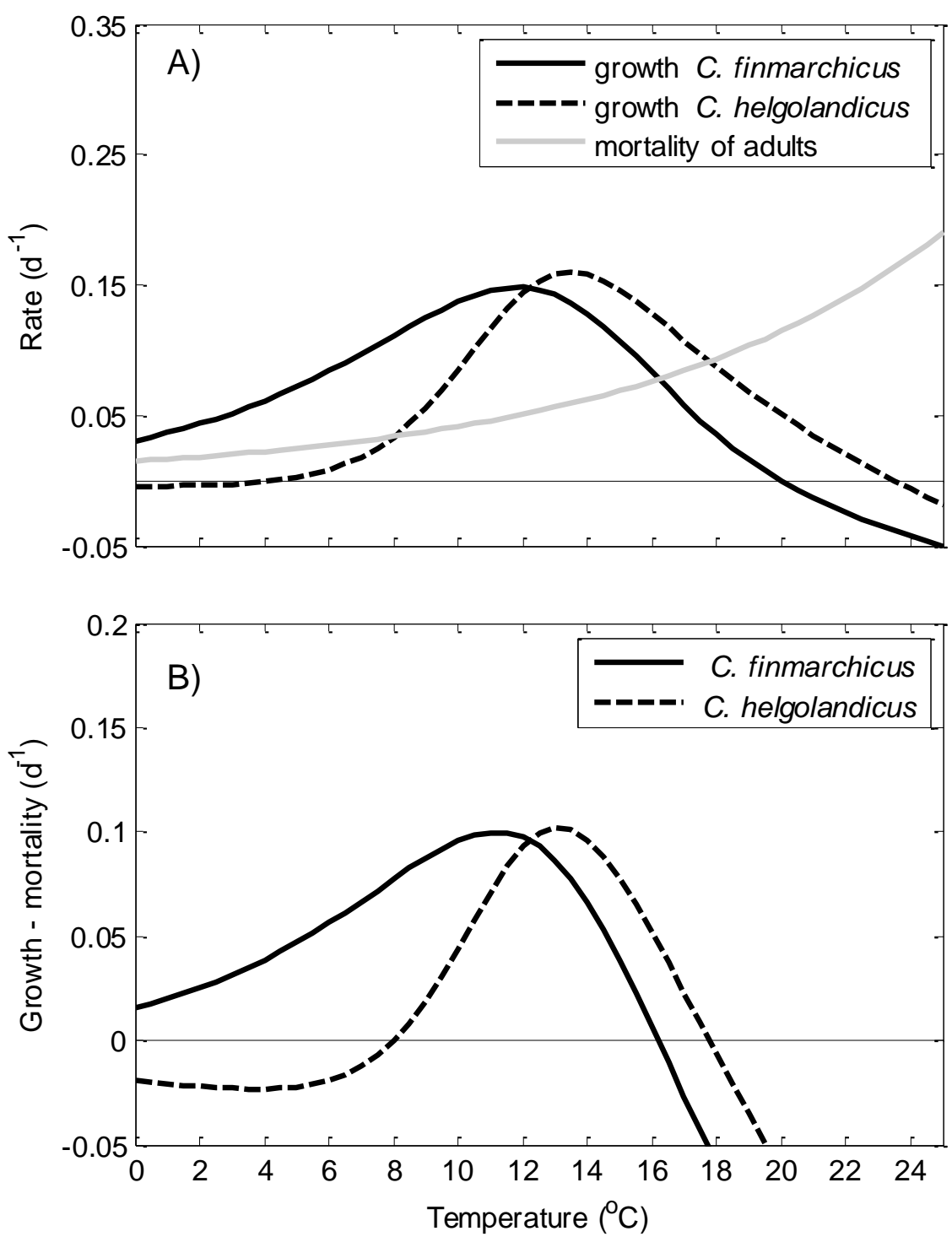


\section{C. finmarchicus}
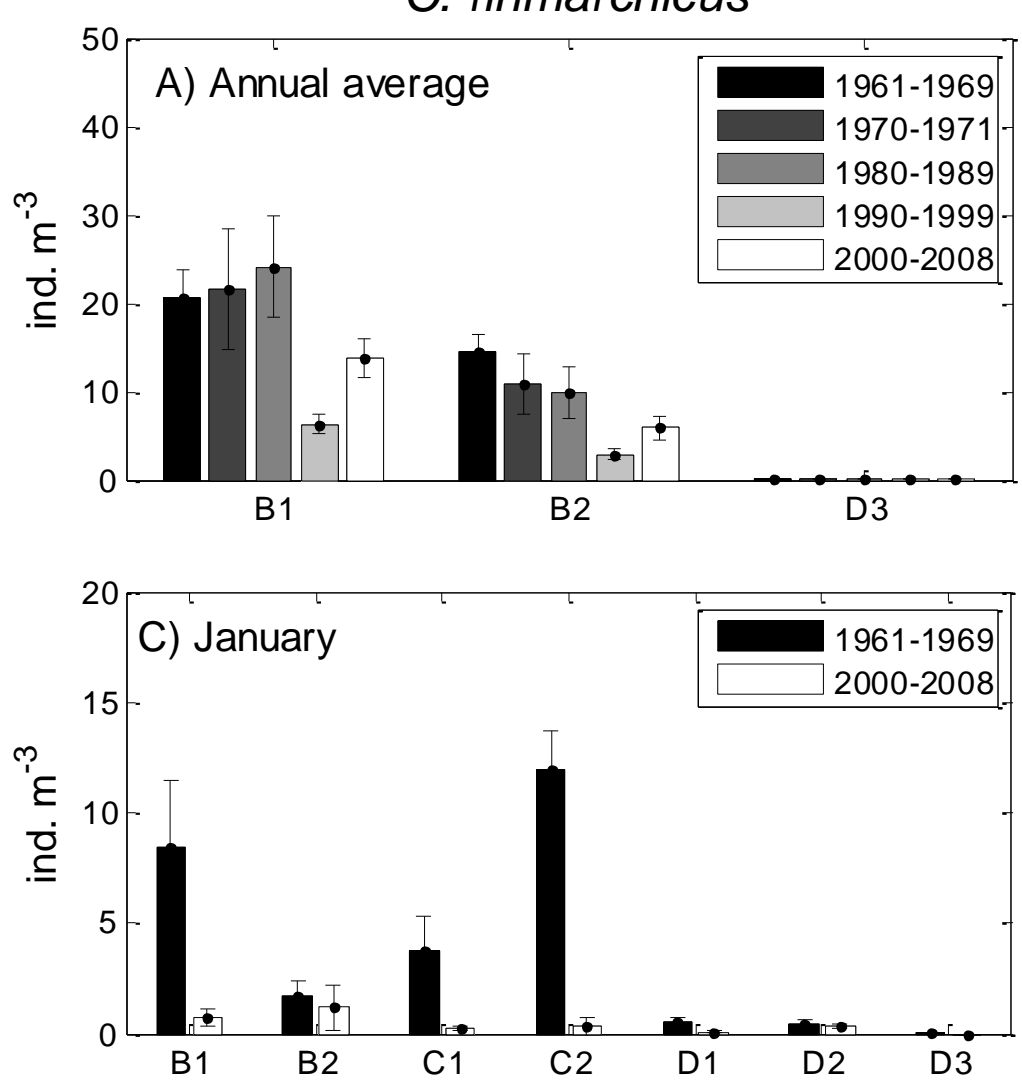

C. helgolandicus
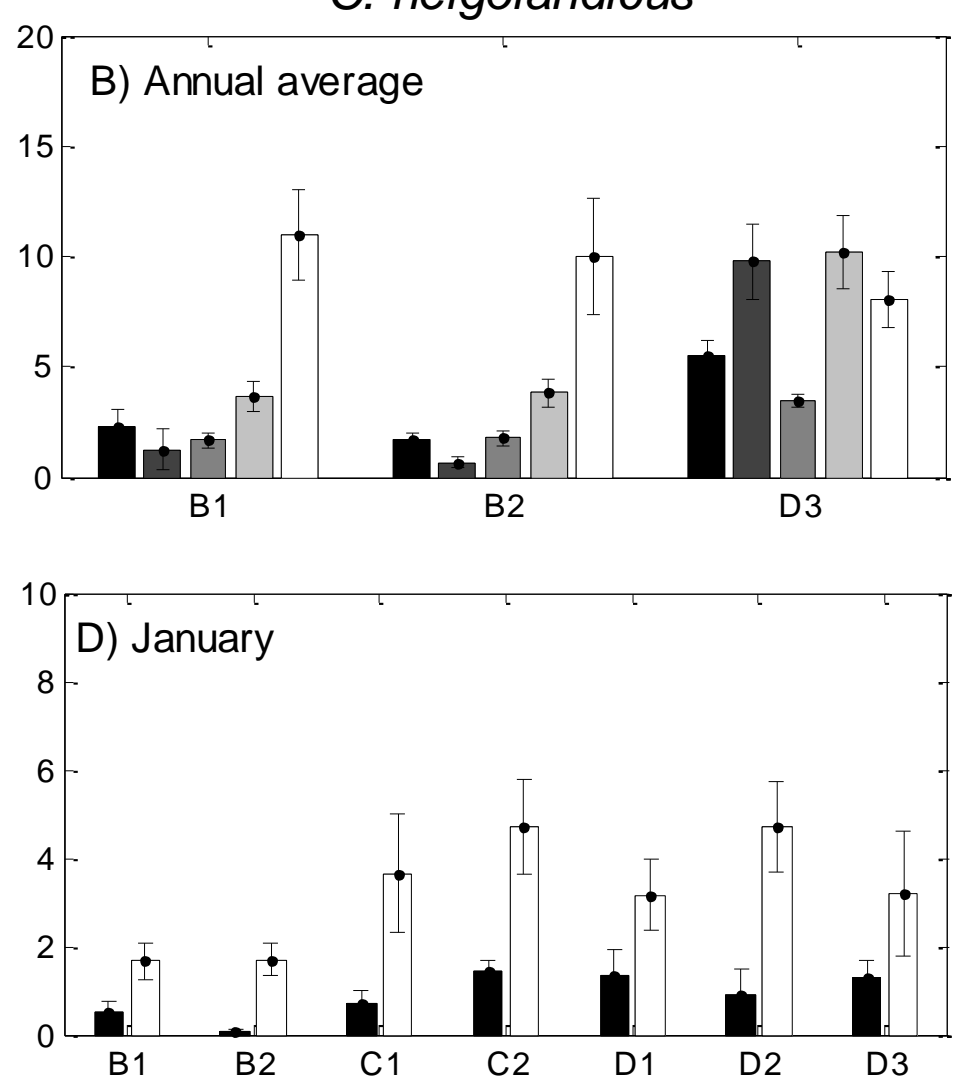
Figure 5.
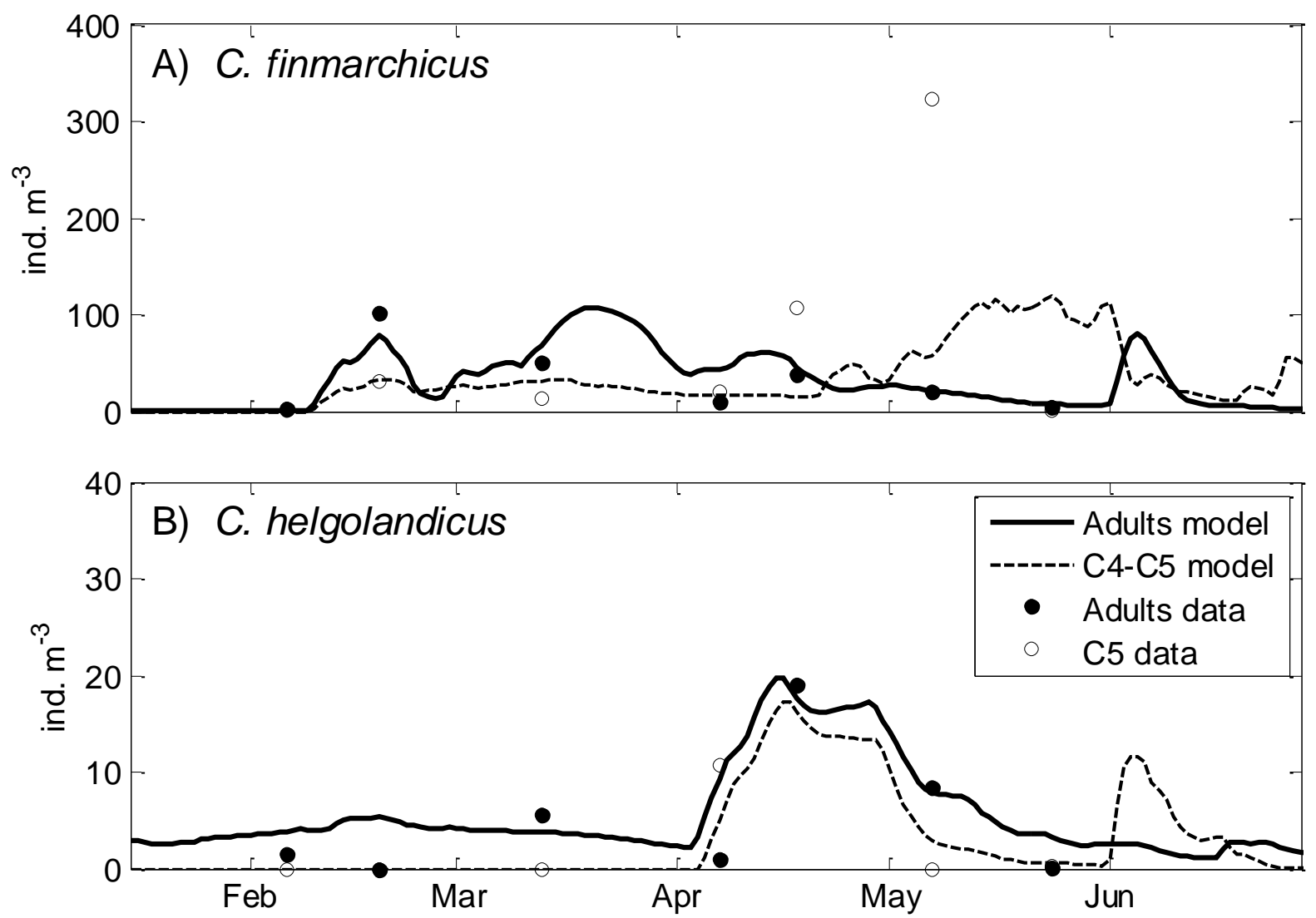
Figure 6.
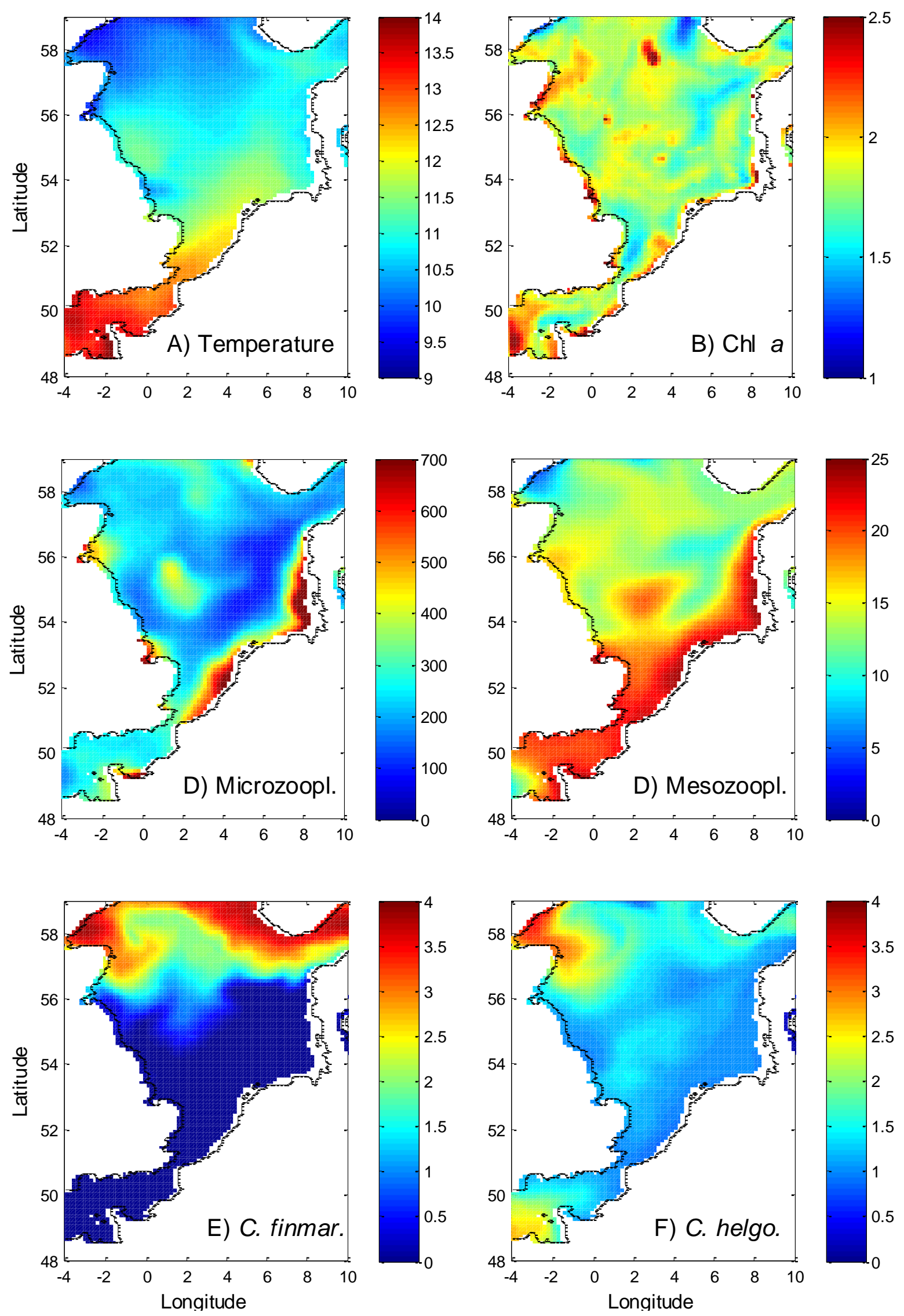
Figure 7.

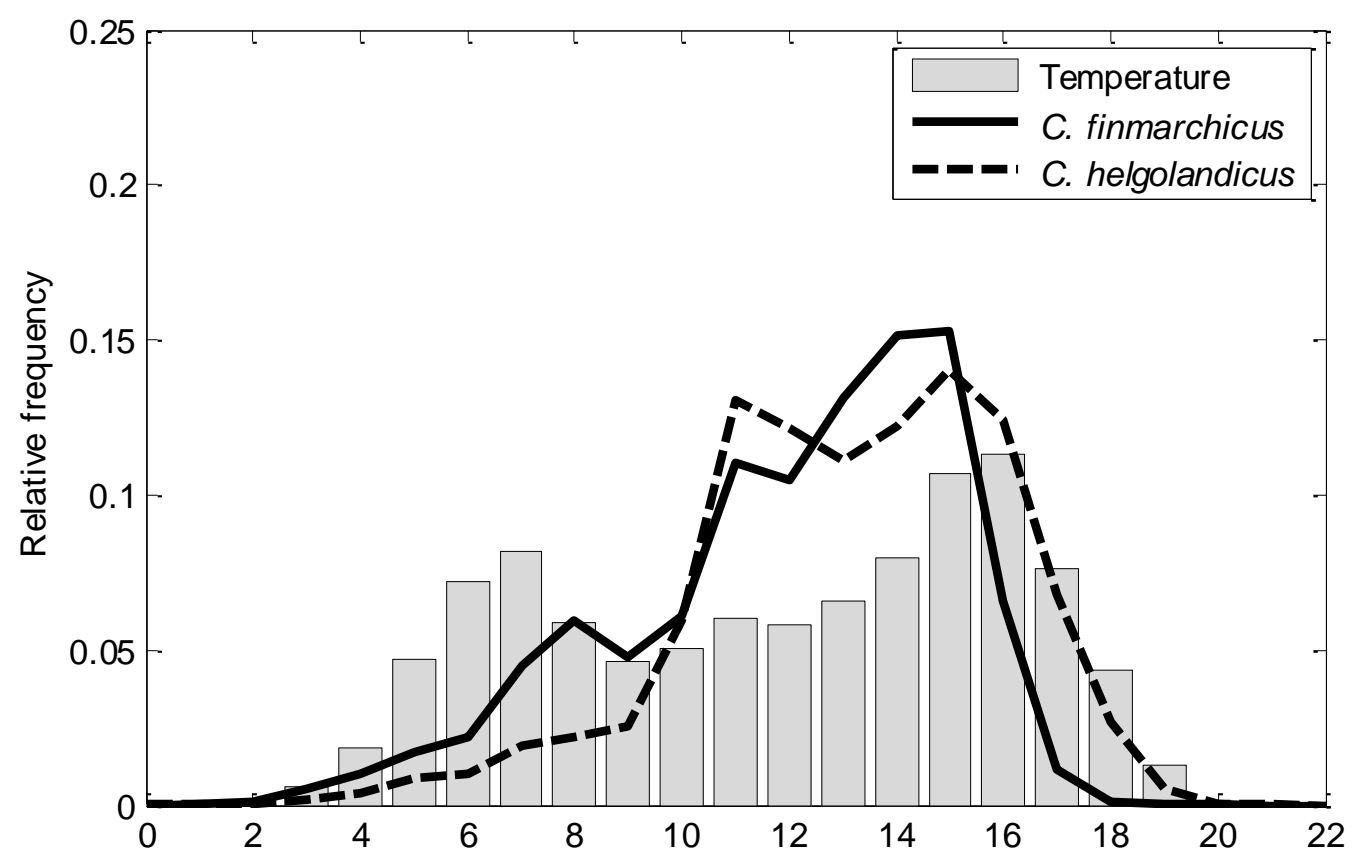


Fig. 8.
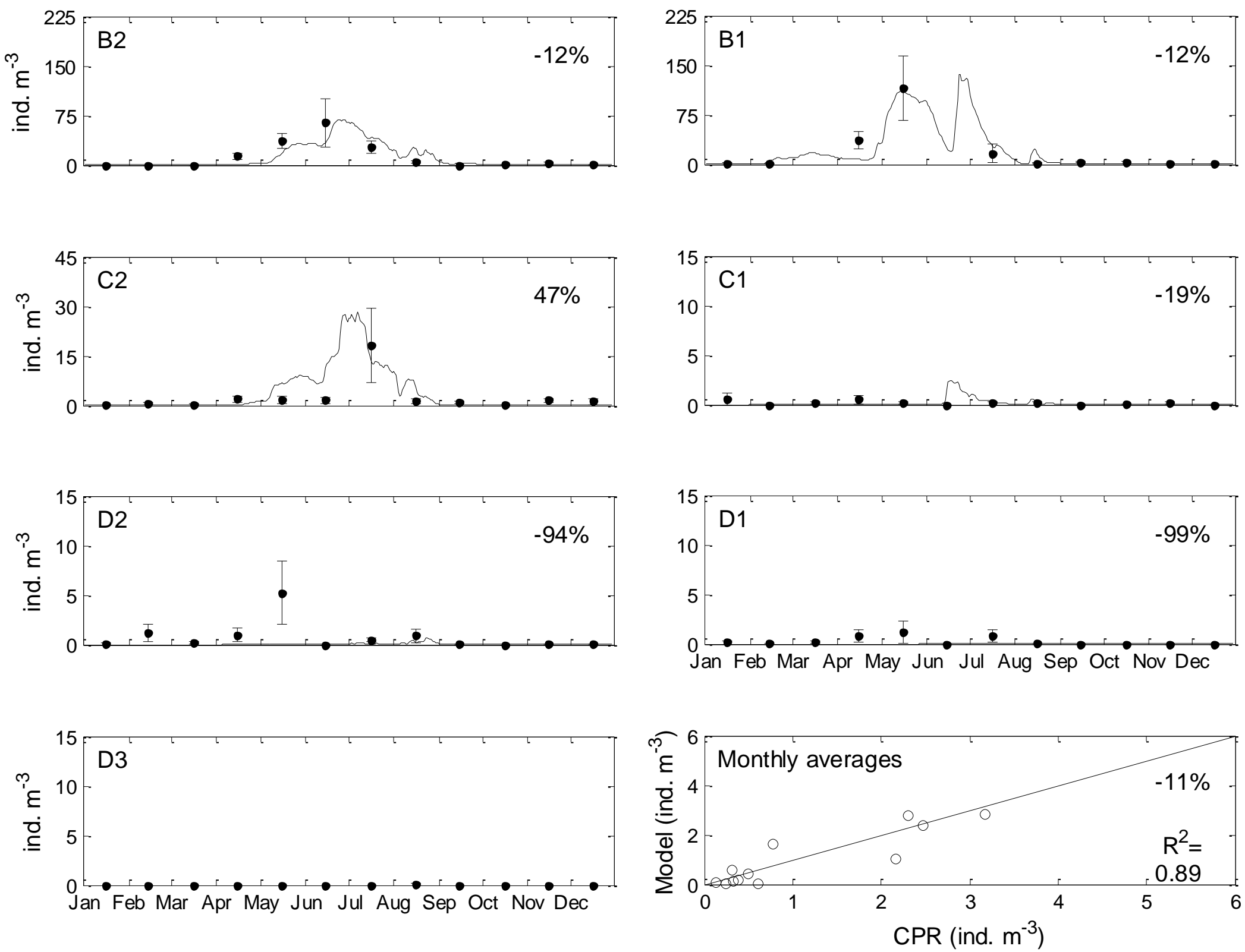
Figure 9.
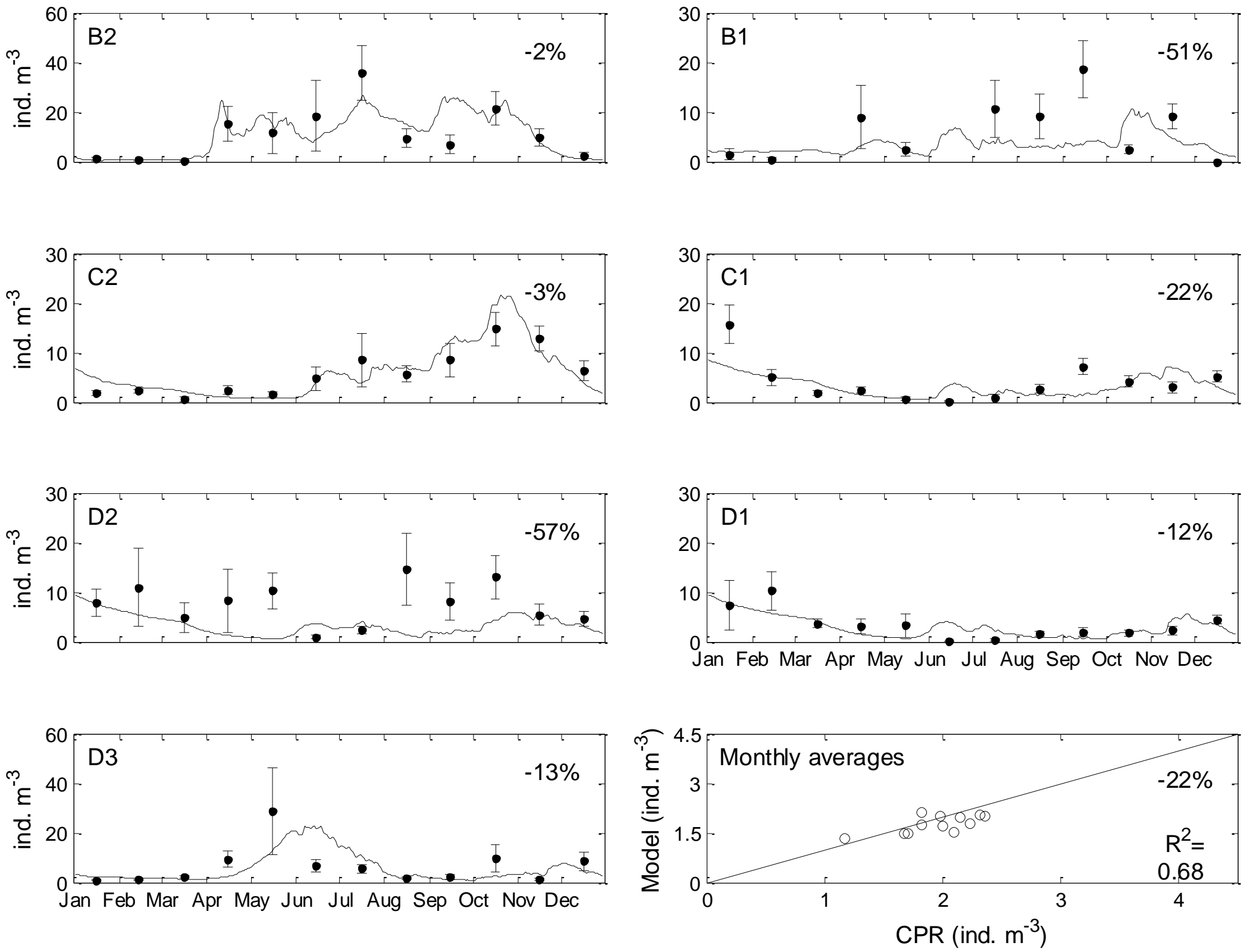
Figure 10.

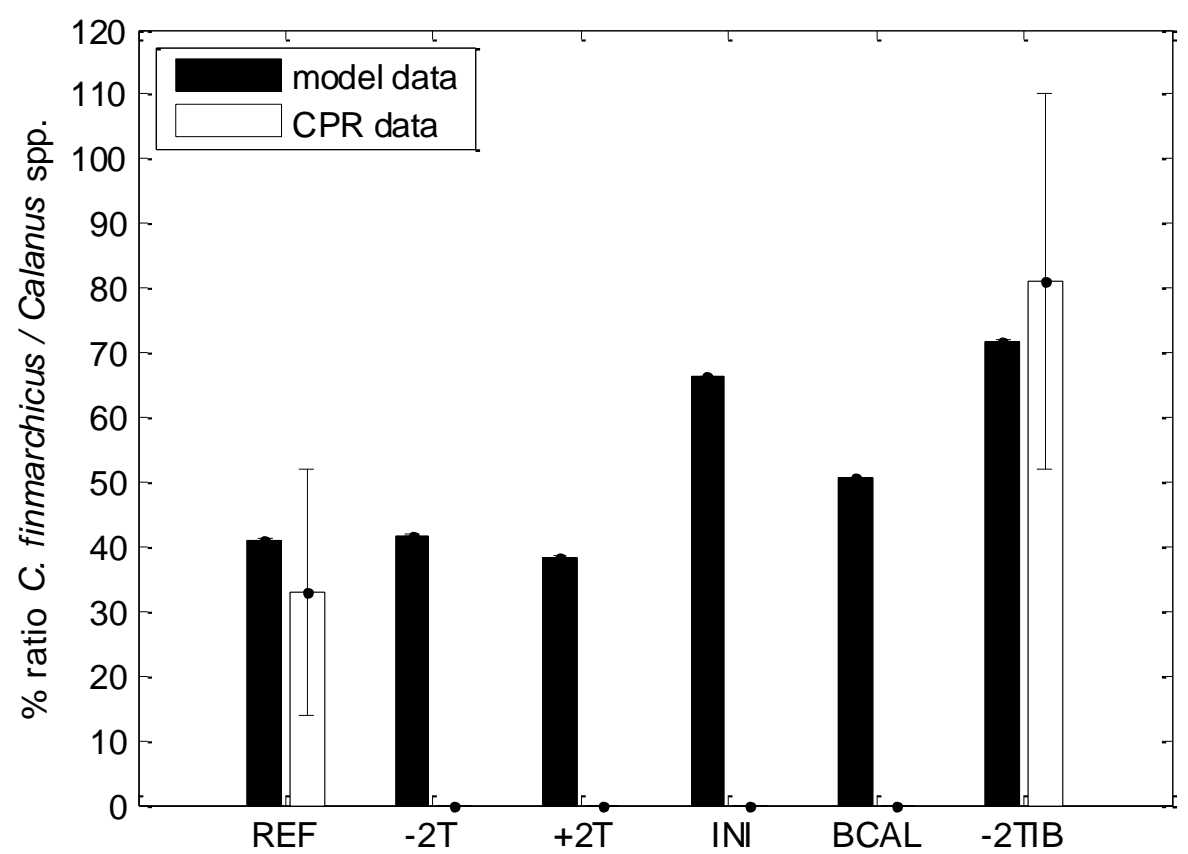


Figure 11.

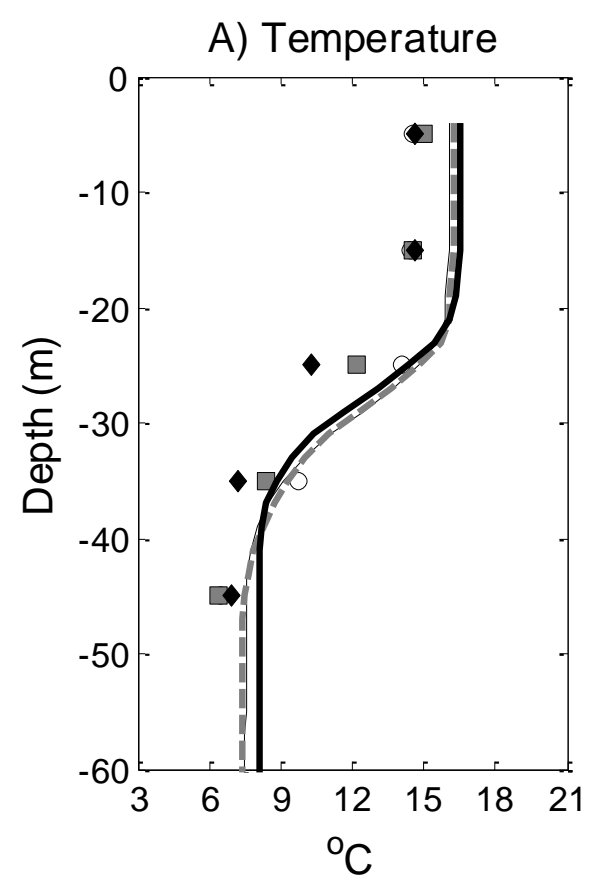

B) $\mathrm{Chl} \mathrm{a}$

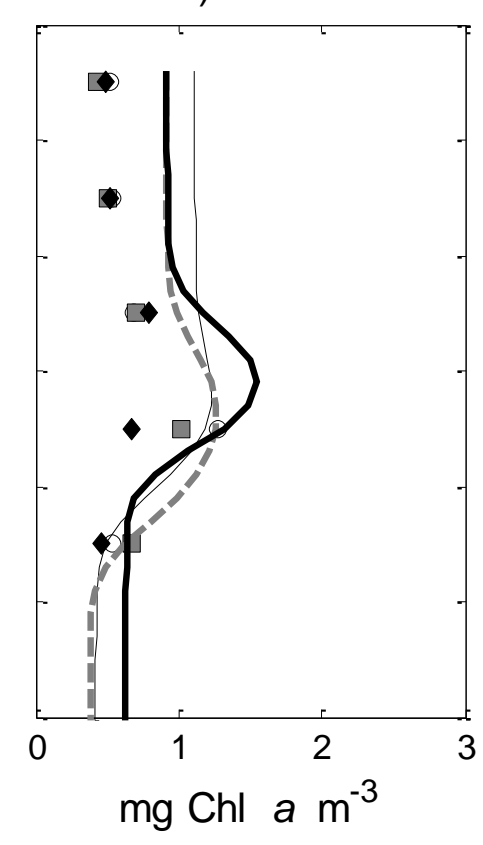

C) C. finmarchicus

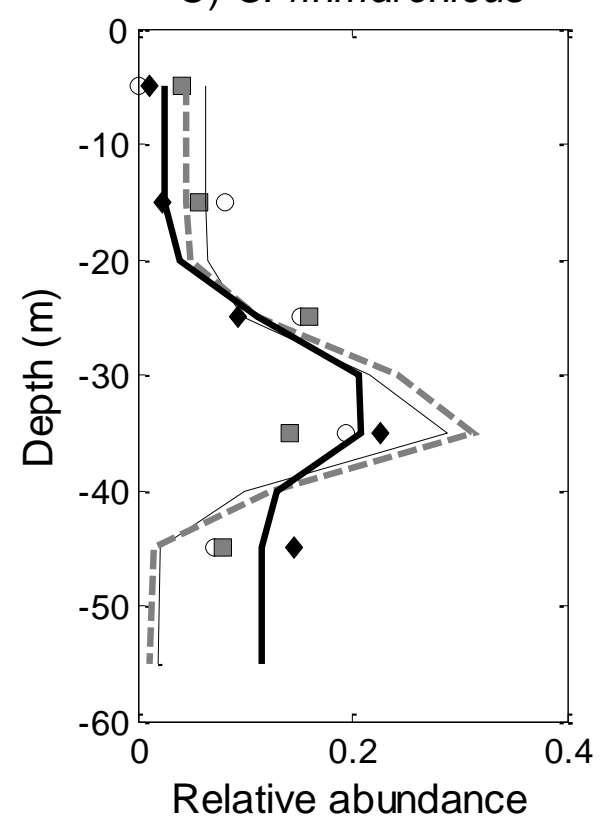

D) C. helgolandicus

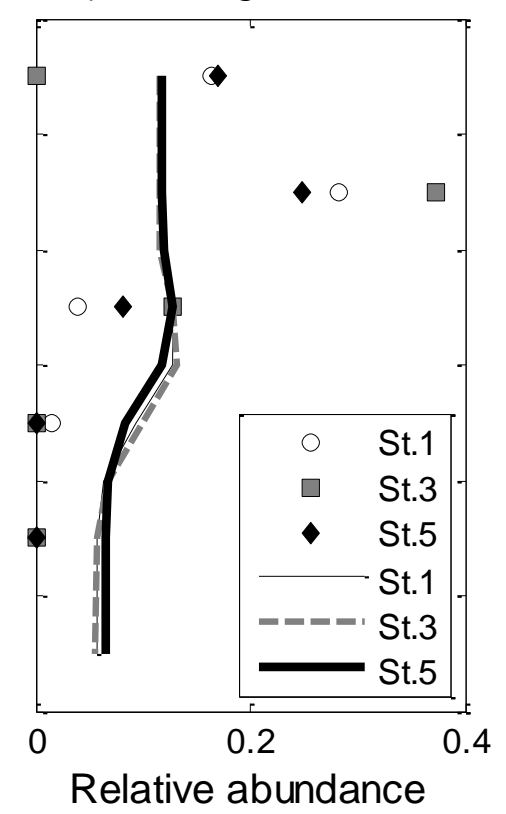


Figure 12.
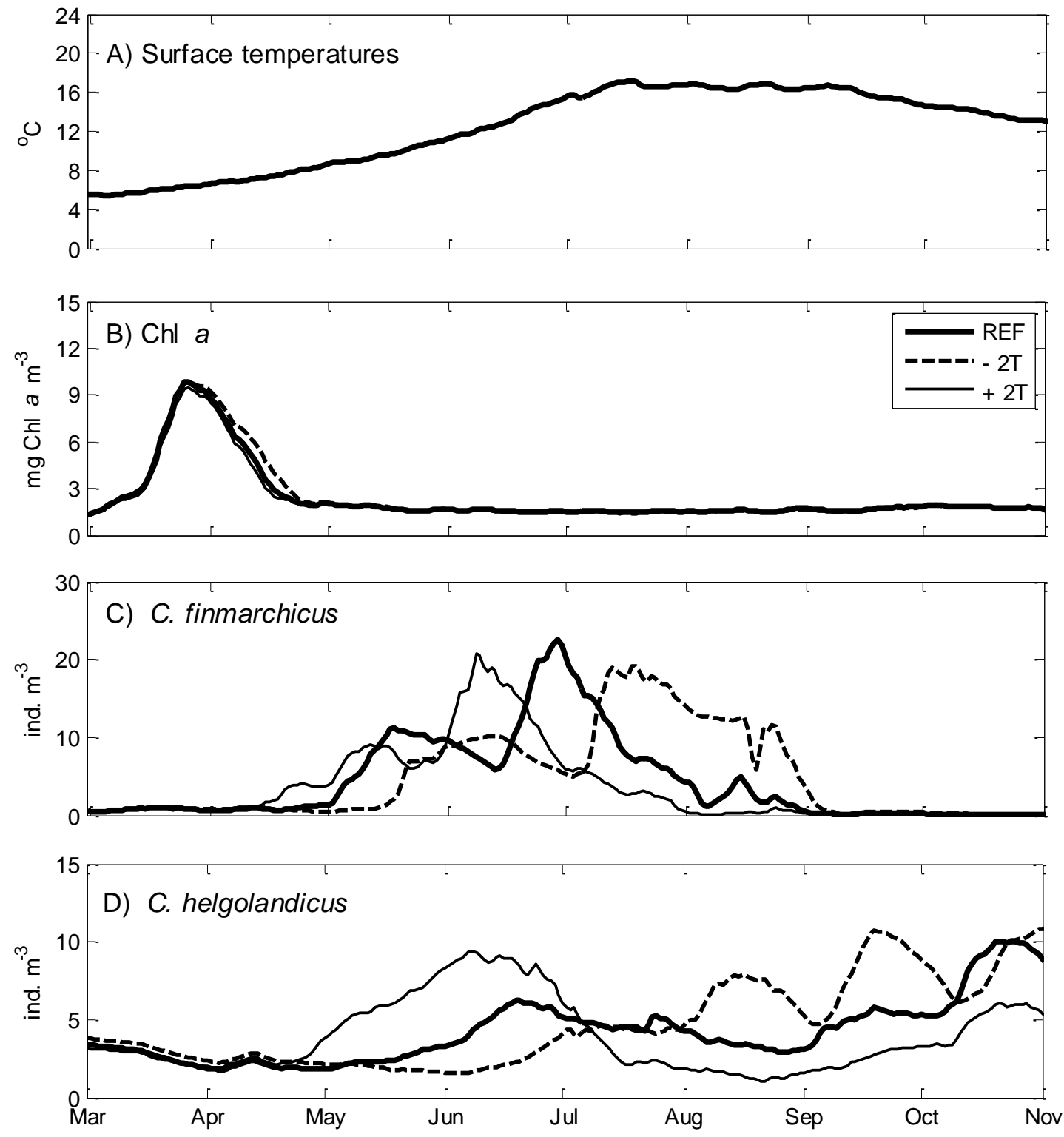
Figure 13.
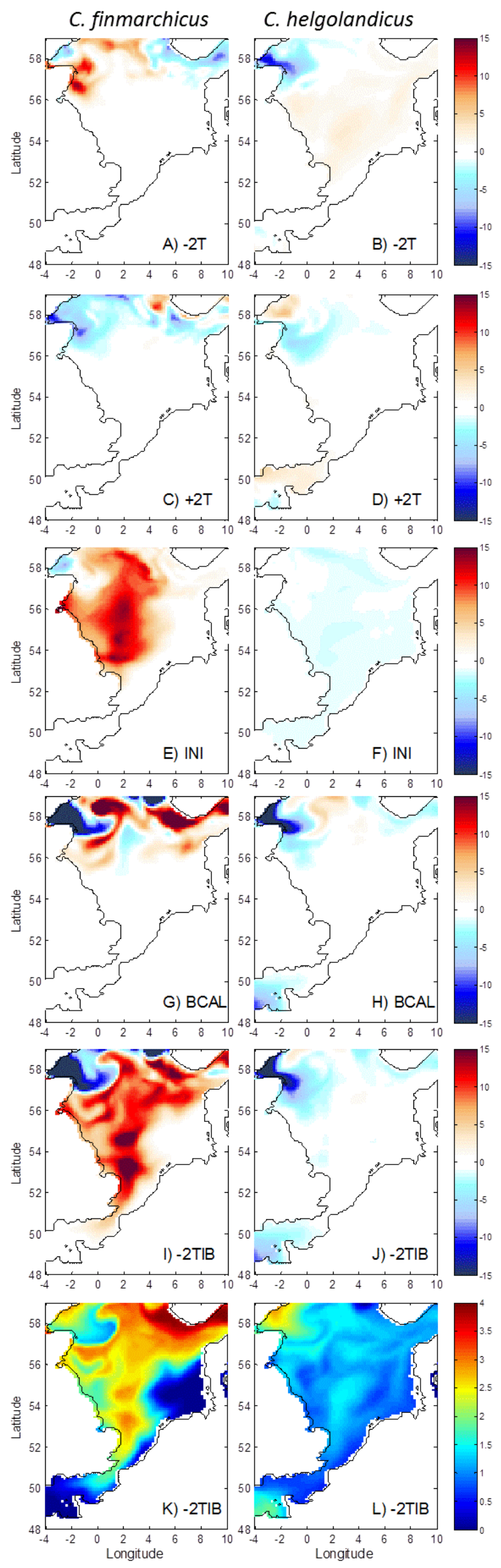
Figure 14.
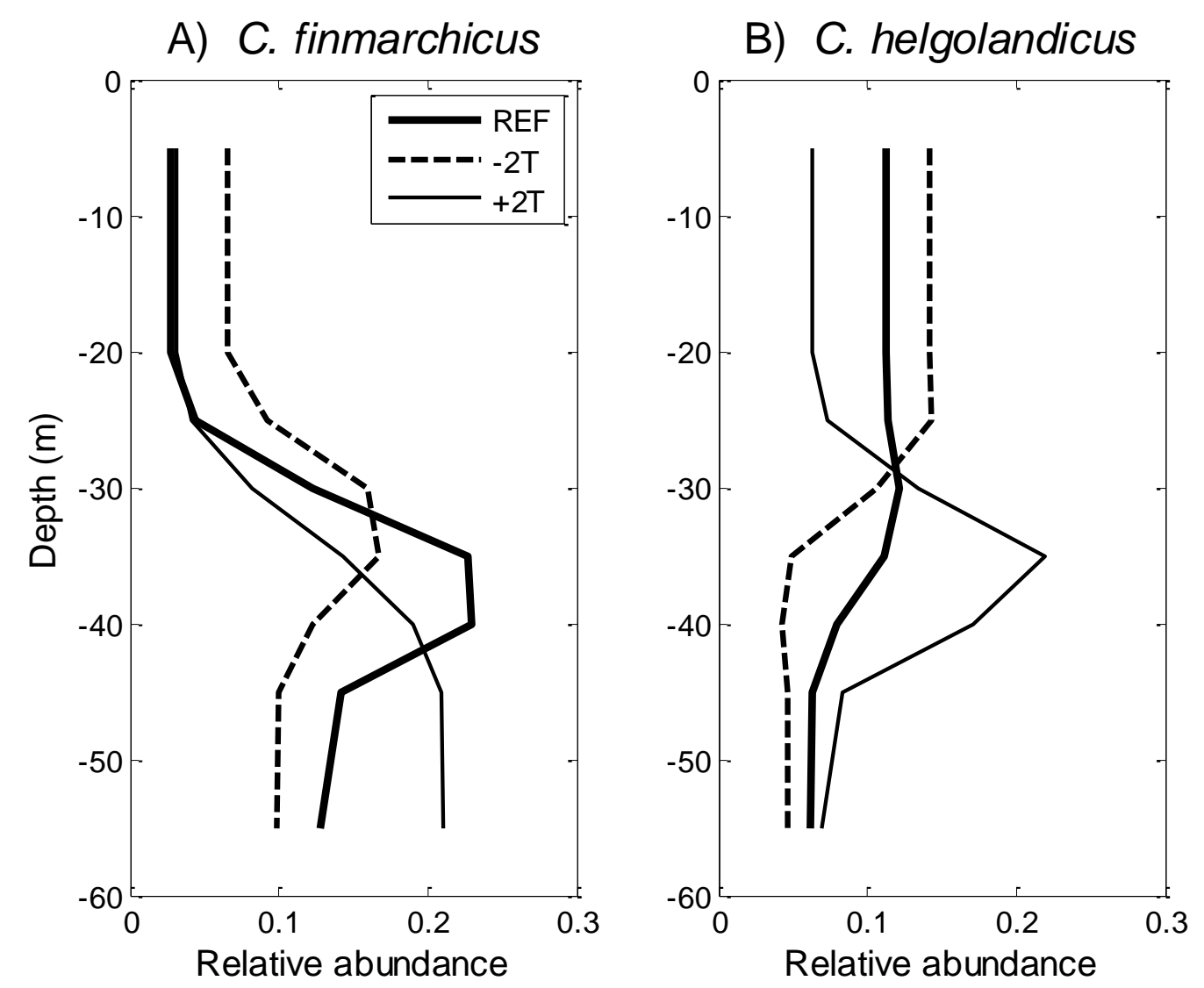